\title{
Analysis of Seepage and Displacement Field Evolutionary Characteristics in Water Inrush Disaster Process of Karst Tunnel
}

\author{
Yongbiao Lai, ${ }^{1}$ Shuo $\mathrm{Li}^{2}{ }^{2}$ Jiaqi Guo $\mathbb{D},{ }^{2,3}{\mathrm{Zhengguo} \mathrm{Zhu},{ }^{3} \text { and Xin Huang }}^{2}$ \\ ${ }^{1}$ China Construction Railway Investment Construction Group Ltd., Beijing 102601, China \\ ${ }^{2}$ School of Civil Engineering, Henan Polytechnic University, Jiaozuo 454003, China \\ ${ }^{3}$ State Key Laboratory of Mechanical Behaviour and System Safety Traffic Engineering Structures, Shijiazhuang Tiedao University, \\ Shijiazhuang, 050043 Hebei, China
}

Correspondence should be addressed to Jiaqi Guo; gjq519@163.com

Received 25 February 2021; Revised 4 May 2021; Accepted 15 June 2021; Published 9 July 2021

Academic Editor: Chuangzhou Wu

Copyright (c) 2021 Yongbiao Lai et al. This is an open access article distributed under the Creative Commons Attribution License, which permits unrestricted use, distribution, and reproduction in any medium, provided the original work is properly cited.

\begin{abstract}
Water inrush of tunnel is one of the most common geological disasters in the karst strata in China. Aiming at the rock mass with a quasi-masonry structure in the water-resistant strata between karst cavity with high pressure water and tunnel and the shortcomings of theoretical analysis, traditional numerical simulation, and physics model test for describing and reflecting this special structure of rock mass, a Discrete Element Method considering the fluid-solid coupling effect and structural characteristics of rock mass is employed to study the disaster process of water inrush and the evolutionary characteristics of catastrophe information like seepage pressure and displacement under condition of different karst water pressure, tunnel depth, and lateral pressure coefficient. Research results show the following: (1) the seepage pressure and displacement increase with the increase of kart water pressure. The seepage pressure demonstrates a decreasing state from top to bottom in water-resistant strata, and the time of arrival to a stable value for the seepage pressure shows the time effect. (2) The larger the tunnel depth, the greater the coalescence and distribution scope of fracture and the more likely the water inrush to occur in a short time. The stability of water-resistant strata decreases on the whole with the growth of tunnel depth. (3) The increase of lateral pressure coefficient can restrain the fracture development and strengthen stability. The fracture state is significantly influenced by a lateral pressure coefficient. The results of numerical simulation are consistent with those obtained by a model test. Research and analysis based on energy are a promising train of thought for studying the disaster process of water inrush in a karst tunnel.
\end{abstract}

\section{Introduction}

Since the 21st century, with the rapid advancement of west development strategy of Chinese national economy, the focus of tunnel construction has gradually shifted to the Western Mountain and karst area. However, complex karst geological structures, especially various scale concealed karst cavities and underground rivers, make the construction of tunnel face the serious threat of water inrush in the abovementioned areas. The karst cavities with high water pressure and high concealment around a tunnel, inducing the suddenness and unpredictable water inrush disaster, are more dangerous than the karst structures exposed by tunnel excavation [1]. In the absence of presupport and prereinforcement, if the water-resistant strata between the tunnel and the concealed cavity with high water pressure cannot withstand the combined effect of karst water pressure and excavation disturbance, fractures will generate, propagate, and then coalesce with each other, eventually causing water inrush disaster and serious economic losses and casualties [2-7]. During the construction process, the Malujing Tunnel of the Yiwan Railway encountered a series of large-scale karst cavities, dissolved fissures, and sinkholes, and more than 10 large scale water and mud inrush disasters occurred successively. Among them, two weighty disasters occurred on January 21, 2006, and April 11, 2008, resulting in 15 deaths and a delay of more than two years [8]. Qiyueshan tunnel encountered a total of 187 large-scale karst pipelines, karst cavities, fault zones with high pressure water and other unfavourable geologies. As a result, 18 times of water inrush disasters 
occurred, and the cumulative value of water discharge reached to $6.3 \times 10^{6} \mathrm{~m}^{3}$, which led to a sharp increase in the cost of construction $[9,10]$. The study on the disaster process of water inrush and evolutionary characteristics of accompanying catastrophe information is of great significance for control and preventing water inrushes in karst tunnel.

Lots of scholars have done many researches on disaster mechanism of water inrush and catastrophe information characteristics by theoretical analysis, numerical simulation, and physical model tests up to now. In terms of theoretical research, $\mathrm{Xu}$ et al. [11] proposed a semianalytical solution to determine the minimum safe thickness of water-resistant strata for resisting water inrush from filling-type karst cavities based on the principle of the slice method. Fu et al. [12] derived the computational formula of the minimum safety thickness for preventing the collapse of rock pillar when a tunnel is excavated above a karst cave. Guo et al. [13] used the Schwarz alternating method to identify the critical water-resistant thickness and analysed the influence of karst water pressure. Xin et al. [14] established an attribute recognition model for safe thickness assessment between a concealed karst cave and tunnel based on the attribute mathematic theory. Yang et al. [15] studied the minimum safe thickness of rock plug and obtained its analytical expression. In the field of numerical simulation, Qin et al. [16] analysed the distribution law of releasable elastic strain energy and failure zone under different widths of concealed karst cave by FLAC3D. Shan et al. [17] proposed a comprehensive numerical analysis method to determinate the safe thickness, and its rationality and effectiveness have been proved by field tests. Pan et al. [18] investigated the mechanism of lagging water inrush in tunnel construction due to the proximity of a karst cavern with confined water via numerical simulations. Li [19] analysed the catastrophic process of water inrush in the water-resistant strata induced by unloading damage under strong seepage by RFPA flow. With respect to physical model tests, Liang et al. [20] analysed the evolutionary laws of stress, displacement, and water pressure by a physical model test of water inrush in tunnel excavation. Yang et al. [21] studied the disaster process and failure model of waterresistant strata. Pan et al. [22] conducted a solid-fluid coupling model tests on lagging water inrush of karst tunnel and researched the evolutionary process of disaster information under different karst water pressures.

The previous researches and achievements as above for the stability and disaster process of the water-resistant strata promoted the advancement in this field and provided a solid foundation for further study in this paper. However, there are some shortcomings about theoretical analysis and physical model test. A theoretical analysis method can be only used to assess the overall instability of water-resistant strata in the end under some simplifications and assumptions. At the meantime, theoretical analysis is difficult to analyse and describe the disaster process of water inrush with highly nonlinear characteristics. As for physical model tests, there exist some disadvantages of expense, time, and acquisition of information. Numerical simulation is an effective and convenient tool for the simulation of disaster process of the water-resistant strata and water inrush with some unique advantages compared with theoretical analysis method and physical model testing method. The water-resistant strata are basically regarded as porous continuous medium in the aforementioned studies by the use of numerical simulation, which ignores the fracture condition in the water-resistant strata and misestimates the fluid-solid coupling effect. Therefore, for reflecting the real structure properties of water-resistant strata, it is very necessary to employ a numerical method that can consider the initial discontinuities (shown in Figure 1) and accurately describe the initiation and propagation of these discontinuities considering fluidsolid coupling (shown in Figure 1).

In the limestone strata, discontinuities such as beddings and cross joints intersect with each other and cut the rock mass into numerous relatively discrete blocks, called quasimasonry structure seen in Figure 1. Figure 1 visually shows the disaster process of water inrush in the water-resistant strata with a quasi-masonry structure. The upper part of Figure 1 illustrates the structure of limestone in the karst area and the spatial relationship of cavity with high pressure water and tunnel. The lower half of Figure 1 is the sketch to intuitively indicate the disaster process of water inrush from karst cavity after tunnel excavation. As show in Figure 1, the disaster process of water inrush is the macroresult of the initiation, propagation, and coalescence of the initial discontinuities under tunnel excavation disturbance and karst water pressure. Therefore, the structure characteristics of the waterresistant strata and water-rock interaction in the rock mass with quasi-masonry structure play the important role in the disaster process of water inrush and evolutionary characteristics of catastrophe information like seepage pressure and displacement. The new method based on the DEM (UDEC) and fictitious joint technology is adopted to really simulate the disaster process of water-resistant strata under the combined effect of different karst water pressure, tunnel depth, and lateral pressure coefficient $[23,24]$. The evolutionary characteristic of seepage pressure and displacement is analysed under different conditions, and the influential mechanism of karst water pressure, tunnel depth, and lateral pressure coefficient is revealed. The achievements are of great significance for early warning and prevention for water inrush of karst tunnel.

\section{Numerical Modeling}

2.1. Model Generation. Figure 2 shows the numerical model used in this simulation to analyse the catastrophic evolution process of water inrush from a water-filled karst cavity above the tunnel in the limestone strata with the quasi-masonry structure. For this model to ensure the simulation effect and computing efficiency, the range is $80 \mathrm{~m} \times 71 \mathrm{~m}$; the three-centred circular tunnel section with height of $9.5 \mathrm{~m}$, span of $8.5 \mathrm{~m}$, and buried depth of $500 \mathrm{~m}$ is adopted to simulate a more real tunnel cross section and tunnel depth. The concealed karst cavity above tunnel with water pressure $(p)$ is generalized to an ellipse with a long axis of $20 \mathrm{~m}$ and a minor axis of $12 \mathrm{~m}$, which can be identified and positioned by collaborative exploration method integrating geological identification, geophysical inversion, and drilling; and the 


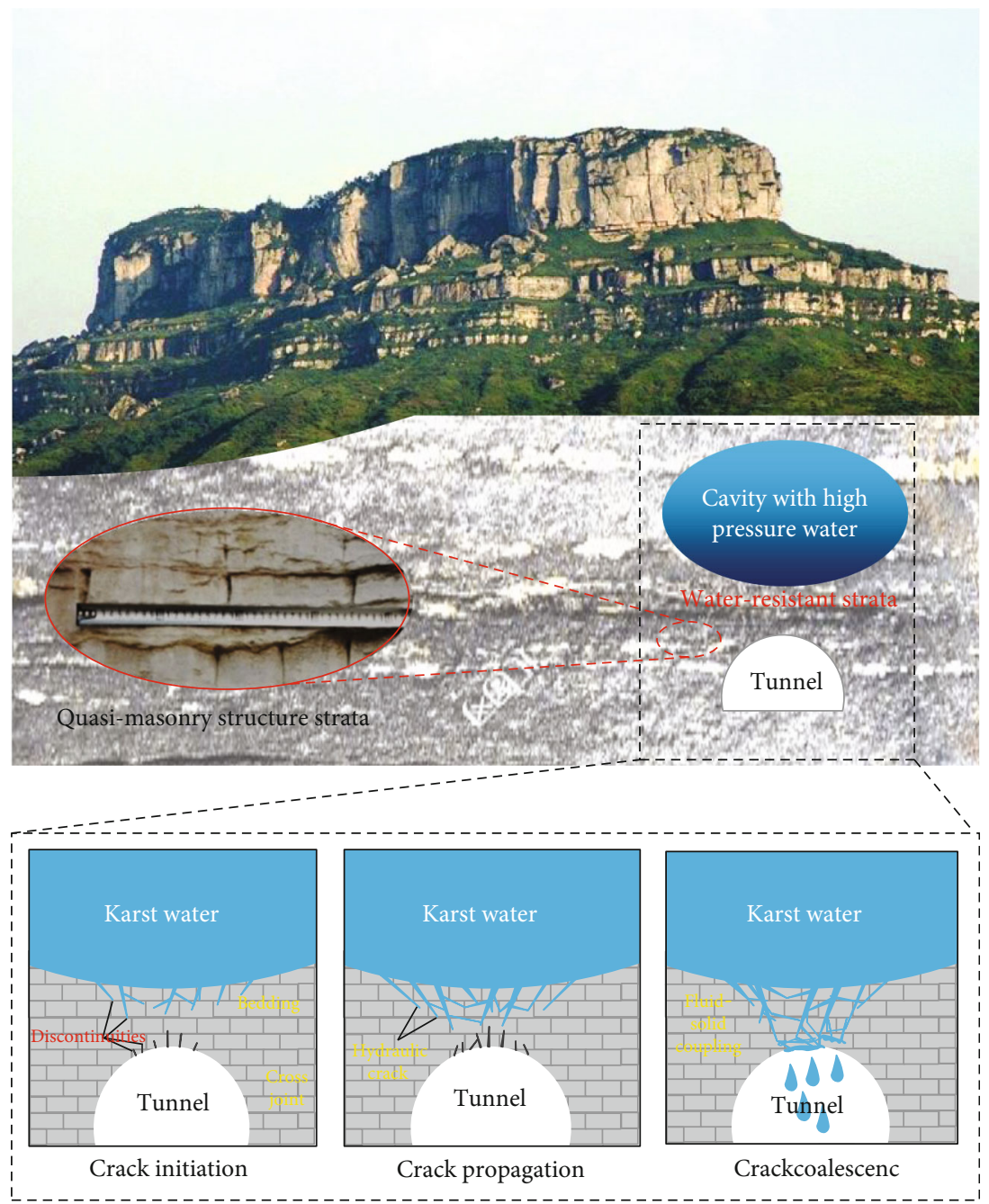

FIGURE 1: Sketch of quasi-masonry structure of water-resistant strata and water inrush process.

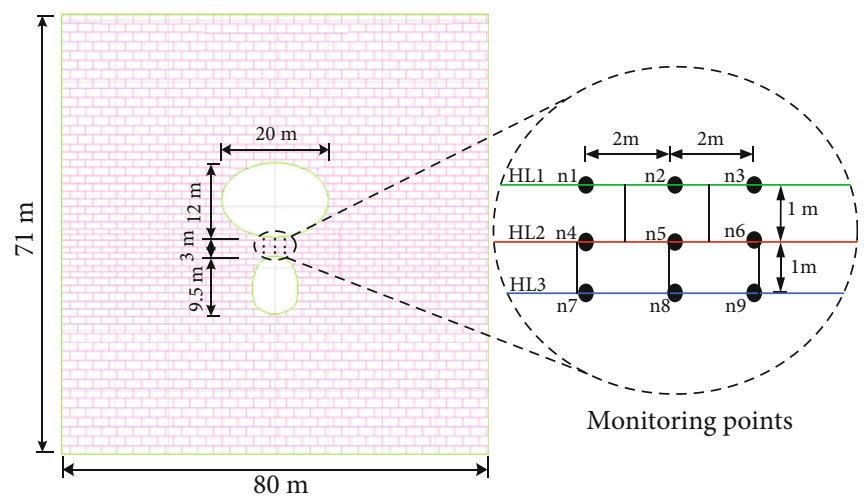

FIGURE 2: Simulation calculation model and measuring point arrangement.

water-resistant strata between cavity and tunnel are $3 \mathrm{~m}$ in thickness. Given the features of the quasi-masonry structure in karst strata, the blocks are divided into many small rectangles by the beddings and the crossed joints. A row of blocks bounded by upper and lower beddings is one limestone layer with the thickness of $1 \mathrm{~m}$, and the number of the layer is 71 .
So, according to the range of model, tunnel dimension, and scale of karst cavity, the initial numerical model generates with the help of the command of Generate; and then, karst cavity generated in the model and the influence of karst cavity generation are reset. Finally, the full model is intersected by beddings and cross joints through Jset and crack, and the 
numerical model has been built as shown in Figure 2, as possibly similar to the actual structural features of the limestone strata. To acquire the disaster information like seepage pressure and displacement during the instability process of water-resistant strata, the typical 9 measuring points $\mathrm{n} 1 \sim 3$, n4 6, and n7 9 (shown in Figure 2) are, respectively, set up on horizontal lines HL1, HL2, and HL3 with a horizontal distance for $2 \mathrm{~m}$ and a vertical distance of $1 \mathrm{~m}$ between the adjacent points, which, respectively, are located on the three beddings and at the intersection point of the bedding and cross joint for easily and effectively reflecting the displacement and seepage information of the sharp change points in the disaster process.

2.2. Material Constitutive Models and Properties. The mechanical properties of model are defined by the use of the mechanical parameters of the blocks and those of the joints between blocks. In this numerical simulation, the material of rock block system is regarded as a large number of deformable microblocks (cons = 3, Mohr-Coulomb plasticity model adopted for the balance between computational accuracy and easy acquisition of mechanical parameters), bound together by contacts. The jcons $=5$ (joint model residual), Coulomb slip with residual strength, is utilized to model the mechanical behaviour of discontinuities. In this model, an internal flag is set for each discontinuity segment when the shear strength of discontinuities is exceeded. If a discontinuity was fractured, the discontinuity friction angle and discontinuity cohesion are set to residual values. Therefore, the microparameters of the block and the discontinuity are required to input; they are shown in Table 1 based on the previous research of authors [25] and Table 2 [26], respectively.

2.3. Boundary Conditions. After finishing the cutting of all the block (beddings and joints) and the defining of the mechanical properties of model, the boundary and initial conditions were added on the numerical model, as shown in Figure 3. The concerned are defined as follows in Figure 3: $k q_{0}+\gamma h$ is the stress value at bottom sides of the left and right boundaries of the numerical model; $q_{0}(\gamma H)$ is the overburden pressure of the model; $k$ is the lateral pressure coefficient; $\gamma$ is the bulk density of rock mass; $h$ is the height of the model. According to the tunnel depth $(H)$, the weight of the overlying rock mass was converted into a vertical uniform load $\left(q_{0}\right)$ applied on the top boundary of the model. A stress boundary was also exerted on the left and right sides of the model with a lateral pressure coefficient $(k)$. The bottom side was bounded by displacement boundary. The karst water pressure $(p)$ in karst cavity is regarded as a constant and acted vertically on the boundary of the cavity. Numerical simulations for fully coupled fluid-solid interaction with saturated flow and initiation and propagation of hydraulic fracture are carried out in the following order: stress balance and state reset, tunnel excavation, acquiring the disaster information, and stop under the condition of combination.

2.4. Calculation Scheme. Karst water pressure, tunnel depth, and lateral pressure coefficient are three important influential factors that affect the stability condition and disaster process of the water-resistant strata. To figure out the disaster process of water inrush in karst tunnel and the evolutionary characteristics of catastrophe information like seepage pressure and displacement under condition of different karst water pressure, tunnel depth, and lateral pressure coefficient, a series of numerical simulations are conducted to the seepage pressure, displacement of the kinetics and dissipated energy of the water-resistant strata were simulated and analysed based on the above modeling method in the condition of different conditions. Table 3 shows the influential factors and their calculation scheme in this research. The cases $1 \sim 3$, 4 6, and 7 9 are used to study the effect of water pressure $(p)$, tunnel depth $(H)$, and lateral pressure coefficient $(k)$ on the disaster process and catastrophe information characteristics of the water-resistant strata, respectively. During the calculation, the fluid flow calculator is on for considering the solid-fluid coupling, and the mechanical time duration $t$ for the increment of cycling lasts for $80 \mathrm{~ms}$.

The seepage pressure characterizes the water pressure value, water pressure distribution, and crack propagation in the water-resistant strata, and vertical displacement to reflect the stability of the water-resistant strata of the $\mathrm{n} 1 \sim \mathrm{n} 9$ of nine monitoring points on HL1, HL2, and HL3 is collected and recorded. Energy is the essential dynamics of crack propagation and rock mass failure under any circumstances. The failure process of rock is accompanied by energy accumulation, energy dissipation and energy release. In order to analyse the stability of the water-resistant strata from the energy point of view in stability analysis based on energy properties, the kinetic energy as one kind of the released energy and the dissipated energy of the model system are calculated and recorded by use of UDEC program in the disaster process of water inrush.

\section{Influence of Karst Water Pressure $(p)$}

3.1. Seepage Field Analysis of the Water-Resistant Strata under Different $p$. Table 4 demonstrates the evolutionary process of the seepage field in the water-resistant strata under the three cases of tunnel depth of $500 \mathrm{~m}$, lateral pressure coefficient of 1.2, and different karst water pressure (case 1: $p=1$ $\mathrm{MPa}$, case $2: p=2 \mathrm{MPa}$, and case $3: p=3 \mathrm{MPa})$ at $t=10 \mathrm{~ms}$, $40 \mathrm{~ms}$, and $80 \mathrm{~ms}$. Thus, this table is subdivided into 9 subfigures; every 3 subfigures in one column show the evolutionary process of seepage field in the water-resistant strata, which also illustrate the progressive failure process of the water-resistant strata. And every 3 subfigures in one row are a comparison of the 3 seepage fields under the different karst water pressure at the same mechanical duration time.

The columns in Table 4 show that the karst water in the cave splits the original closed bedding layers and cross joints and makes the water-resistant strata failure to form many cracks in the upper and middle part under the combined effect of tunnel excavation and karst water pressure at the beginning of the stress release of the surrounding rock mass $(t=10 \mathrm{~ms})$. Then, with further stress release $(t=40 \mathrm{~ms}$ and $t=80 \mathrm{~ms}$ ), the cracks furtherly propagate and the fracture range continuously extends in the water-resistant strata, and the failure degree of the water-resistant strata increases 
TABLE 1: Block and joint mechanical parameters in numerical simulation.

\begin{tabular}{lcccc}
\hline Unit weight $(\gamma)$ & Elastic bulk modulus $(E)$ & Poisson's ratio $(\mu)$ & Internal angle of friction $(\varphi)$ & Cohesion $(c)$ \\
\hline $24 \mathrm{kN} / \mathrm{m}^{3}$ & $18 \mathrm{GPa}$ & 0.2 & 35 & $10 \mathrm{MPa}$ \\
\hline
\end{tabular}

TABLE 2: Joint mechanical parameters in numerical simulation.

\begin{tabular}{lccccc}
\hline $\begin{array}{l}\text { Joint normal stiffness } \\
(\mathrm{jkn})\end{array}$ & $\begin{array}{c}\text { Joint shear stiffness } \\
(\mathrm{jks})\end{array}$ & $\begin{array}{c}\text { Joint cohesion } \\
(\mathrm{coh})\end{array}$ & $\begin{array}{c}\text { Joint friction angle } \\
(f)\end{array}$ & $\begin{array}{c}\text { Joint residual cohesion } \\
(\mathrm{resc})\end{array}$ & $\begin{array}{c}\text { Joint residual friction angle } \\
(\mathrm{resf})\end{array}$ \\
\hline $222.2 \mathrm{~Pa} \cdot \mathrm{m}^{-1}$ & $222.2 \mathrm{GPa} \cdot \mathrm{m}^{-1}$ & $0.15 \mathrm{MPa}$ & $25^{\circ}$ & $0 \mathrm{MPa}$ & $25^{\circ}$ \\
\hline
\end{tabular}

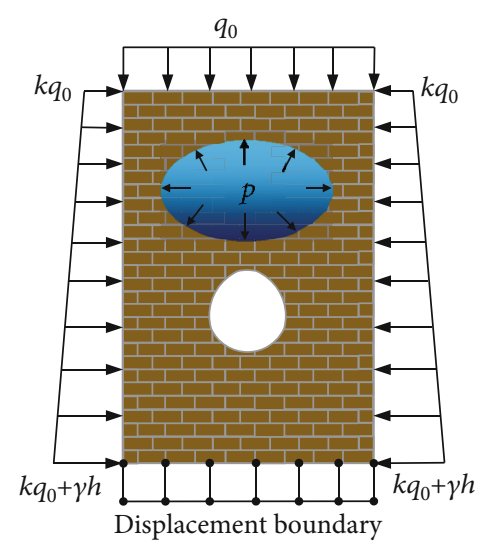

Figure 3: Boundary conditions of numerical simulation model.

with the increase of time in the meantime. At $t=80 \mathrm{~ms}$, the water-resistant strata have the tendency of instability and the water inrush channel initially forms in the case of $p=2$ $\mathrm{MPa}$ and $p=3 \mathrm{MPa}$. In this disaster process, the propagation feature of cracks and the distribution range of water pressure significantly show the time effect and the structure influence of the water-resistant strata.

With the increase of time, it is clear to find that the seepage scope in the water-resistant strata extends obviously and the fracture degree increases quickly with the increase of karst water pressure from the three columns in Table 4. For the first column ( $p=1 \mathrm{MPa})$, relatively fewer cracks induced by karst water pressure and tunnel excavation are generated in the upper and middle parts of the water-resistant strata, and the cracks does not propagate the vault of the tunnel. Therefore, the macroscopic water inrush channel does not form, and the water-resistant strata are in the stable condition. The seepage pressure of each measuring points illustrates a decreasing state from HL1 to HL3, but the seepage pressure is the constant value because the cracks stop propagating and seepage pressure develops fully. For the middle column $(p=2 \mathrm{MPa})$, the larger fracture zone and seepage scope generate, and the fracture degree is more serious and the water inrush channel basically forms. For the third column $(p=3 \mathrm{MPa})$, these above characteristics are more prominent. Taking the seepage pressure of $n 7 \sim n 9$ measuring points on HL3 as example, the seepage pressure of $n 7 \sim n 9$ measuring points at $t=80 \mathrm{~ms}$ is still increasing while the water-resistant strata are in the fracture process by compar- ing with the first column $(p=1 \mathrm{MPa})$. These phenomena revel that the karst water pressure is the important reason of the water-resistant strata.

Figure 4 shows the trend of seepage pressure at the 9 measuring points. It is found that the seepage pressure of the 9 measuring points in the water-resistant strata increases with the increase of kart water pressure $p$ from Figure 4 . The time of arrival to a steady-state value for the seepage pressure at different measuring point varies obviously, and even the seepage pressure at some measuring points has been fluctuating in Figure 4. The reasons for the abovementioned phenomenon are as follows: (1) after tunnel excavation, under the action of excavation disturbance and karst water pressure, the karst water gradually infiltrates into the originally closed fissures, and the seepage pressure increases gradually. When the seepage pressure exceeds the critical pressure of fracture, the cracks begin to initiate and propagate. No matter whether the water-resistant strata are unstable or not finally (It is related to karst water pressure), under the action of three levels of karst water pressure in this paper, the cracks in the water-resistant strata can always extend to $\mathrm{n} 1 \sim \mathrm{n} 6$ measuring points in the middle and upper parts of the water-resistant strata. Therefore, the seepage pressure at these measuring points can always reach a certain stable value before the formation of macrowater inrush channel in the water-resistant strata or when the fracture stops propagating, as shown in Figures 4(a) and 4(b). Because the location of $n 4 \sim n 6$ is lower than that of $n 1 \sim n 3$ in water-resistant strata, the propagation time for the cracks channelling the cave with high water pressure to reach $n 4 \sim \mathrm{n} 6$ is relatively long, and therefore, it takes a long time for the seepage pressure of $n 4 \sim n 6$ to increase to a stable value. The stable values of seepage pressure at $n 1 \sim n 3$ measuring points are close to the karst water pressure, but the stable value of seepage pressure at $n 4 \sim \mathrm{n} 6$ is relatively smaller, as shown in Figures $4(\mathrm{a})$ and $4(\mathrm{~b})$; (2) when the karst water pressure is $1 \mathrm{MPa}$, the cracks in the water-resistant strata can only propagate to a certain position, and water inrush does not occur. Because the water-resistant strata are stable, the seepage pressure of $\mathrm{n} 7 \sim \mathrm{n} 9$ measuring points set up at the bottom of the waterresistant strata reaches a smaller stable value than that of $\mathrm{n} 1 \sim \mathrm{n} 6$ measuring points. When the karst water pressure is 2 $\mathrm{MPa}$ and $3 \mathrm{MPa}$, at $t=80 \mathrm{~ms}$, the seepage pressure of $\mathrm{n} 7 \sim \mathrm{n} 9$ is also increasing while the water-resistant strata are still fracturing, especially when $p=3 \mathrm{MPa}$, as shown in Figure 4(c). 
TABLE 3: The calculation scheme for the three influential factors.

\begin{tabular}{|c|c|c|c|c|}
\hline Study objectives & Case number & Karst water pressure $(p)$ & Tunnel depth $(H)$ & Lateral pressure coefficient $(k)$ \\
\hline \multirow{3}{*}{ Effect of karst water pressure $(p)$} & 1 & $1 \mathrm{MPa}$ & $500 \mathrm{~m}$ & 1.2 \\
\hline & 2 & $2 \mathrm{MPa}$ & $500 \mathrm{~m}$ & 1.2 \\
\hline & 3 & $3 \mathrm{MPa}$ & $500 \mathrm{~m}$ & 1.2 \\
\hline \multirow{3}{*}{ Effect of tunnel depth $(H)$} & 4 & $2 \mathrm{MPa}$ & $300 \mathrm{~m}$ & 1.2 \\
\hline & 5 & $2 \mathrm{MPa}$ & $500 \mathrm{~m}$ & 1.2 \\
\hline & 6 & $2 \mathrm{MPa}$ & $800 \mathrm{~m}$ & 1.2 \\
\hline \multirow{3}{*}{ Effect of lateral pressure coefficient $(k)$} & 7 & $2 \mathrm{MPa}$ & $500 \mathrm{~m}$ & 0.8 \\
\hline & 8 & $2 \mathrm{MPa}$ & $500 \mathrm{~m}$ & 1.2 \\
\hline & 9 & $2 \mathrm{MPa}$ & $500 \mathrm{~m}$ & 1.6 \\
\hline
\end{tabular}

TABLE 4: The seepage pressure distribution in the water-resistant strata under the three cases of $p=1,2$, and $3 \mathrm{MPa}$ at $t=10,40$, and $80 \mathrm{~ms}$.

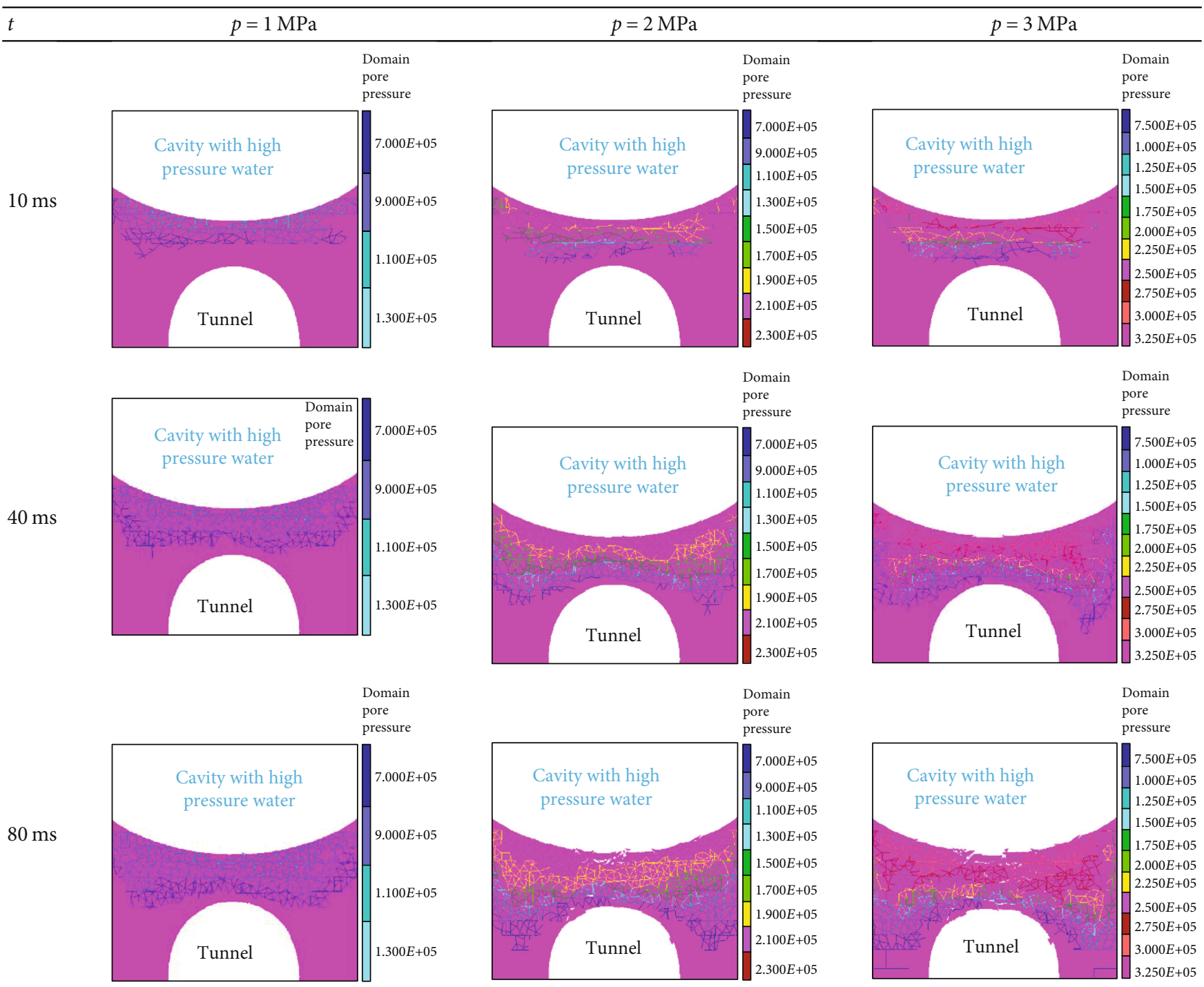

3.2. Displacement Field Analysis of the Water-Resistant Strata under Different $p$. Table 5 shows the displacement field under the three cases of $p=1,2$, and $3 \mathrm{MPa}$ at $t=10,40$, and $80 \mathrm{~ms}$. Taking the second column in Table $5(p=2 \mathrm{MPa})$ as an example, we analyse the displacement evolution characteristics of the water-resistant strata in the disaster process of water inrush. After the tunnel excavation, the waterresistant strata have displaced to some extent due to 


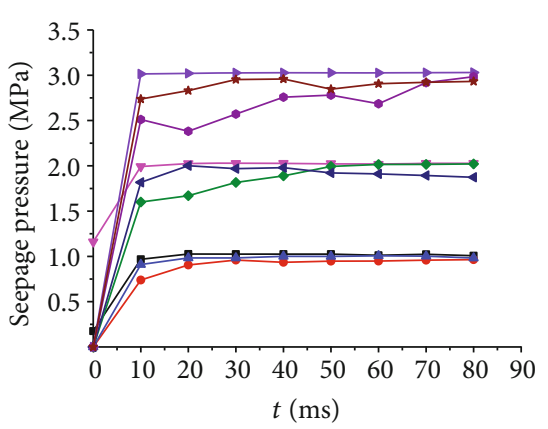

$\rightarrow p=1 \mathrm{MPa}, \mathrm{n} 1$;

$\longrightarrow p=1 \mathrm{MPa}, \mathrm{n} 2$;

$\neg p=1 \mathrm{MPa}, \mathrm{n} 3$;

$\rightarrow p=2 \mathrm{MPa}, \mathrm{n} 1$;

$\rightarrow p=2 \mathrm{MPa}, \mathrm{n} 2$;

$\leftarrow p=2 \mathrm{MPa}, \mathrm{n} 3$;

$\rightarrow p=3 \mathrm{MPa}, \mathrm{n} 1$

$\because p=3 \mathrm{MPa}, \mathrm{n} 2$

* $p=3 \mathrm{MPa}, \mathrm{n} 3$

(a)

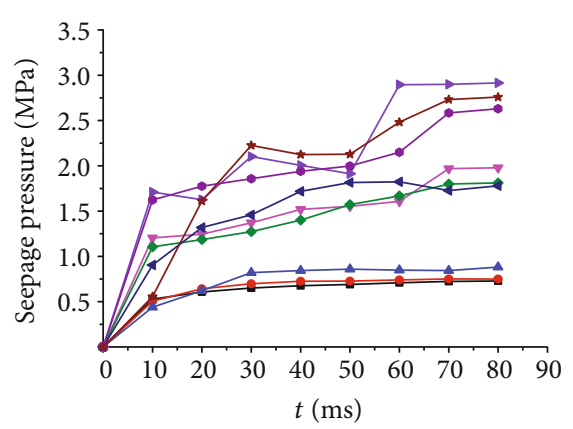

$\rightarrow p=1 \mathrm{MPa}, \mathrm{n} 4$

- $p=1 \mathrm{MPa}, \mathrm{n} 5$;

$\triangle p=1 \mathrm{MPa}, \mathrm{n} 6$;

$\rightarrow p=2 \mathrm{MPa}, \mathrm{n} 4$;

$\rightarrow p=2 \mathrm{MPa}, \mathrm{n} 5$;

$\leftarrow p=2 \mathrm{MPa}, \mathrm{n} 6$;

$\rightarrow p=3 \mathrm{MPa}, \mathrm{n} 4$

$\rightarrow p=3 \mathrm{MPa}, \mathrm{n} 5$

$\rightarrow p=3 \mathrm{MPa}, \mathrm{n} 6$

(b)

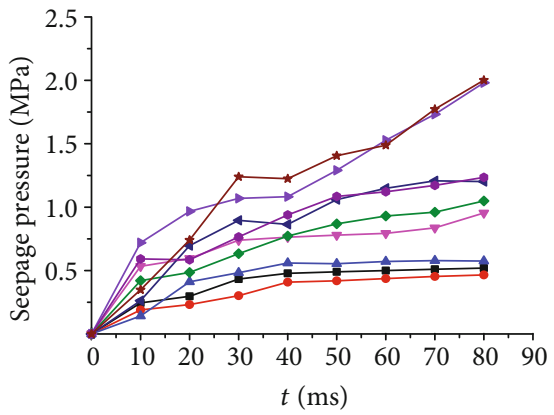

$\because p=1 \mathrm{MPa}, \mathrm{n} 7$

- $p=1 \mathrm{MPa}, \mathrm{n} 8$;

$\multimap p=1 \mathrm{MPa}, \mathrm{n} 9$;

$\rightarrow p=2 \mathrm{MPa}, \mathrm{n} 7$;

$\rightarrow p=2 \mathrm{MPa}, \mathrm{n} 8$;

$\leftarrow p=2 \mathrm{MPa}, \mathrm{n} 9$;

$\rightarrow p=3 \mathrm{MPa}, \mathrm{n} 7$

$\rightarrow p=3 \mathrm{MPa}, \mathrm{n} 8$

* $p=3 \mathrm{MPa}, \mathrm{n} 9$

(c)

Figure 4: The trend of seepage pressure at the 9 measuring points in the conditions of $p=1$, 2, and 3 MPa: (a) n1 n3 on HL1; (b) n4 n6 on HL2; (c) n7 n9 on HL3.

excavation effect in the early stage of stress release of the surrounding rock mass $(t=10 \mathrm{~ms}$ ), with significant deformation towards the interior of tunnel and slight displacement near the karst cave. As the stress continues to be released ( $t=40$ $\mathrm{ms})$, the seepage scope in the water-resistant strata is getting larger and larger, and the damage region extends rapidly. The seepage crack and seepage pressure in the water-resistant strata totally increase with various degrees, which causes the displacement of the water-resistant strata near tunnel vault continue to increase. And the fracture degree of the water-resistant strata furtherly increases, but overall, the water-resistant strata are still in a stable state. However, when $t=80 \mathrm{~ms}$, the overall displacement of the water-resistant strata increases significantly, and meanwhile, the cracks propagate quickly and coalesce with each other making the water-resistant strata into fracture condition. The waterresistant strata become unstable due to severe fragmentation.

Although the disaster process of water-resistant strata is similar under the three cases of $p=1,2$, and $3 \mathrm{MPa}$, the influence difference of karst water pressure on the stability of water-resistant strata cannot be ignored. When $p=1 \mathrm{MPa}$, the vertical displacement of the water-resistant strata in the condition of stability is relatively small. But as $p$ increases to $2 \mathrm{MPa}$ and $3 \mathrm{MPa}$, the water-resistant strata have undergone the failure at $t=80 \mathrm{~ms}$, and it can be clearly observed that the fracture degree and vertical displacement of the water-resistant strata at the top of the tunnel increase continuously with the increase of $p$. The number, width, and connectivity degree of the hydraulic fractures increase at the same time, and the speed of fracture and instability accelerates. The increase of the water pressure in the karst cave has a greater impact on the collapse of the water-resistant strata. The persistent fluid-solid coupling effect ultimately leads to the failure and overall instability of the water-resistant strata. From Table 5, we can also find that the fracture zone is grow- ing greater and greater with the increase of $p$. The fracture zone between the cave and the tunnel has a downward displacement and is divided into many smaller fragments, which released the stress acting on the rock mass below the fracture zone, and hence, the rock mass shows a slightly upward displacement.

Figure 5 shows the variation process of vertical displacement at the 9 measuring points in the water-resistant strata with $p=1,2$, and $3 \mathrm{MPa}$. Comparing the vertical displacement of the same measuring points, it is obvious that the vertical displacement increases significantly with the increase of $p$, which illustrates that the karst water pressure has an obvious influence on the displacement of the water-resistant strata. In detail, when $p=1 \mathrm{MPa}$, the displacement increases almost linearly and steadily with increase of the time. But when $p$ is $2 \mathrm{MPa}$ or $3 \mathrm{MPa}$, the displacement of the same measuring point parabolically and quickly grows with the growth speed accelerating and the growth rate increasing. This is because the higher karst water pressure makes it easier to generate cracks in the water-resistant strata and furtherly forms the water inrush channel. Meantime, the higher karst water pressure can also exert a downward load on the water-resistant strata. Both of these factors contribute to the displacement of the water-resistant strata. The displacement of $n 2$ on HL1 is greater than that of $n 1$ or $n 3$ under the effect of the same $p$. The same thing as above, the vertical displacement of $n 5$ and $\mathrm{n} 8$ on HL2 and HL3 is larger that indicates the displacement of arch crown is greater than that of both sides of arch shoulders. In another words, the arch crown of tunnel is fractured severely compared with other locations.

\section{Influence of Tunnel Depth $(H)$}

4.1. Seepage Field Analysis of the Water-Resistant Strata under Different $H$. Table 6 shows the evolution processes of 
TABLE 5: The vertical displacement contour under the three cases of $p=1,2$, and $3 \mathrm{MPa}$ at $t=10,40$, and $80 \mathrm{~ms}$.

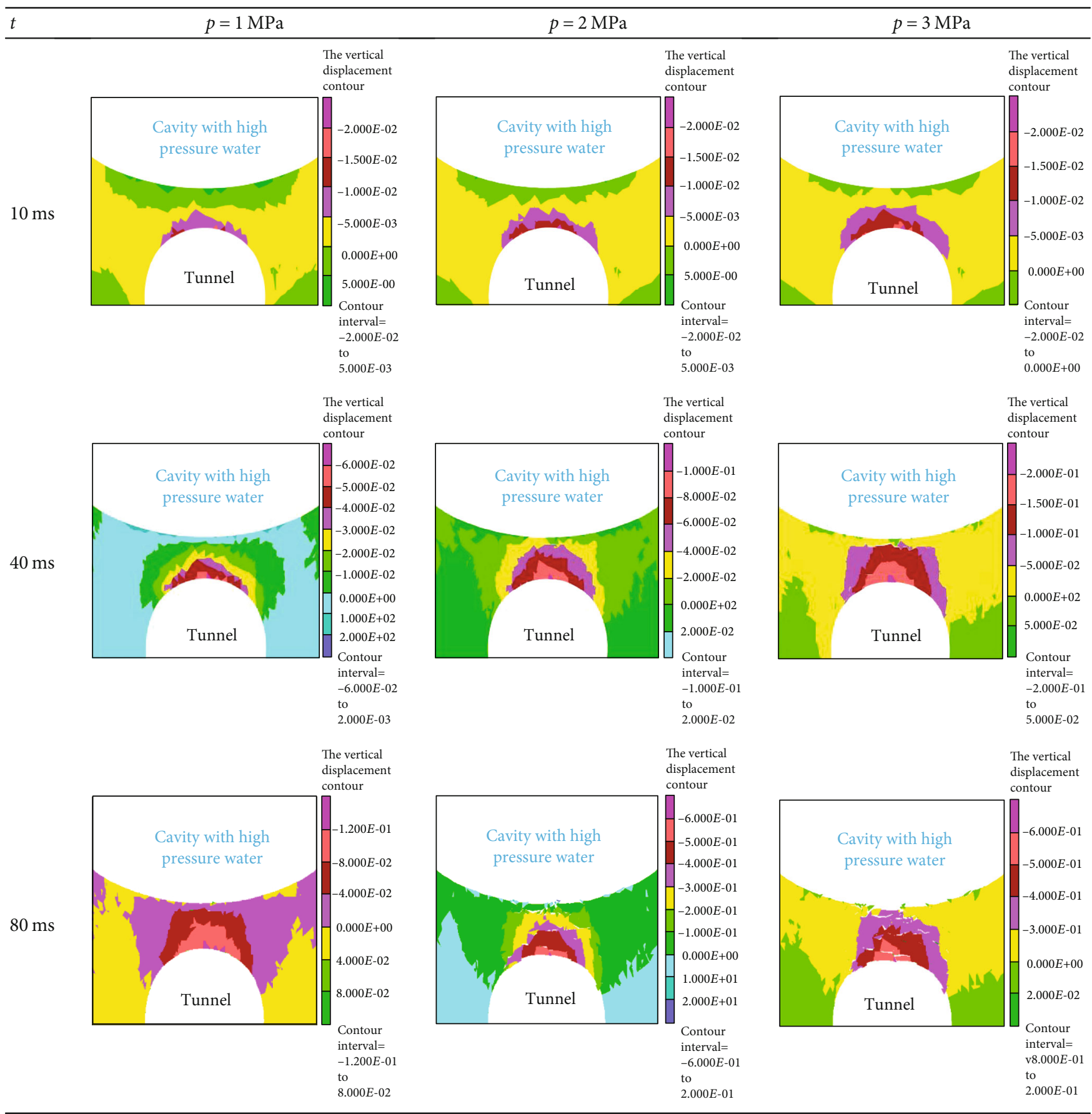

the seepage field in the water-resistant strata under the three cases of karst water pressure of $2 \mathrm{MPa}$, lateral pressure coefficient of 1.2, and tunnel depth (case 4: $H=300 \mathrm{~m}$, case 5: $H$ $=500 \mathrm{~m}$, and case $6: H=800 \mathrm{~m})$ at $t=10 \mathrm{~ms}, 40 \mathrm{~ms}$, and 80 ms. The column is the mechanical duration time, and the row is the different tunnel depth. Similar to the evolutionary process of seepage field in Section 3.1, for each tunnel depth, the karst water also infiltrates downward in the waterresistant strata to the vault, spandrel, and hance of the tunnel gradually. But the velocity of water seepage and crack propagation varies greatly with tunnel depth, and the formation time of water inrush channel is different in the condition of three kinds of tunnel depth. In the initial stage $(t=10 \mathrm{~ms})$, the karst water ingresses into the water-resistant strata for a short distance, far from the tunnel vault for the situation of $H=300 \mathrm{~m}$. But when $H$ increases to $500 \mathrm{~m}$ or $800 \mathrm{~m}$, the water is about to penetrate the water-resistant strata. Therefore, it can be concluded that the deeper the tunnel is buried, the more likely it is that water inrush happens in the initial stage. What is more, by comparing the distribution area of water with the same $t$, but varied $H$, it is clear that the distribution area of water and hydraulic fractures in the water- 


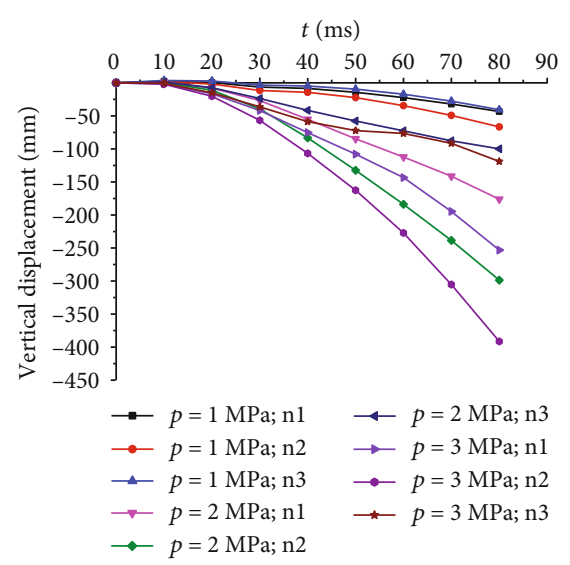

(a)

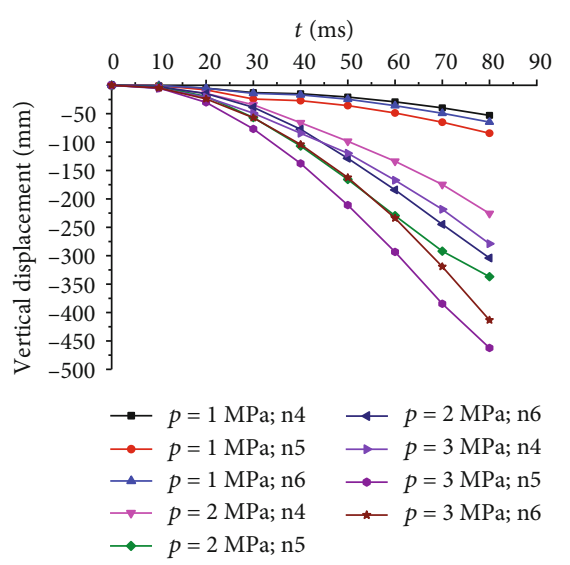

(b)

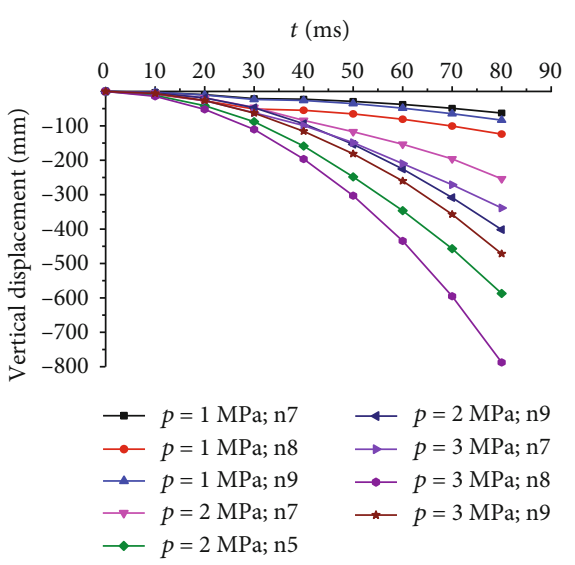

(c)

FiguRE 5: The trend of vertical displacement at the 9 measuring points in the conditions of $p=1,2$, and 3 MPa: (a) n1 n3 on HL1; (b) n4 n6 on HL2; (c) n7 n9 on HL3 with $p=1,2$ and $3 \mathrm{MPa}$.

resistant strata obviously increase with the increase of tunnel depth. At $t=80 \mathrm{~ms}$, water inrush basically occurs under all three cases, but the fracture and water inrush scale in the condition of $H=500 \mathrm{~m}$ is larger than those in $H=300 \mathrm{~m}$ and reaches the maximum in $H=800 \mathrm{~m}$, which reveals that the scale of fracture and water inrush increases with the growth of tunnel depth. This phenomenon shows that under the effect of water pressure and tunnel excavation disturbance, the larger the tunnel depth, the greater the scale and coalescence of fractures formed in the water-resistant strata, which can speed up the formation of channel and the occurrence of water inrush disaster.

Figure 6 shows diachronic evolution characteristics of the seepage pressure at the 9 measuring points in the condition of $H=300,500$, and $800 \mathrm{~m}$ under tunnel excavation disturbance and karst water pressure $(p=2 \mathrm{MPa})$. It is found that the seepage pressure of $n 1 \sim n 3$ measuring points on HL1 quickly reaches a certain stable value close to karst water pressure in a short time from Figure 6(a), and the seepage pressure of $n 1 \sim n 3$ is little different in the condition of $H=$ 300,500 , and $800 \mathrm{~m}$ finally. The growth of seepage pressure of $\mathrm{n} 4 \sim \mathrm{n} 9$ measuring points is relatively slow by comparison with that of $n 1 \sim n 3$ measuring points, and the deeper the tunnel depth, the greater the seepage pressure of measuring points on HL2 and HL3 in Figures 6(b) and 6(c). These indicate that as the tunnel depth increases, the number and connectivity of hydraulic fractures formed in the water-resistant strata become larger, and the smoother hydraulic fractures can be formed in the water-resistant strata in a relatively short time, resulting in water inrush disaster, which is in accordance with the above analysis.

\subsection{Displacement Field Analysis of the Water-Resistant Strata} under Different $H$. Table 7 shows the displacement contour under the three cases of $H=300,500$, and $800 \mathrm{~m}$ at $t=10$, 40 , and $80 \mathrm{~ms}$. In Table 7, the evolutionary process of the water-resistant strata base on the displacement is similar to that demonstrated in Table 6 , but it still varies considerably between each other due to the different tunnel depth. At the initial stage ( $t=10 \mathrm{~ms})$, the water-resistant strata have a small upward displacement in the upper part (near the cavity side) and a larger displacement on the lower part (near the tunnel side); the magnitude and distribution of these two kinds of displacement widen with increasing of tunnel depth. The reasons for these can be analysed as follows: the waterresistant strata can be simplified as a rock column under loads at the top, left, and right sides after tunnel excavation. The top side is subjected to $2 \mathrm{MPa}$ of water pressure from the cavity, and the lower side is unstressed, while the left and right sides are subject to higher stress, approximately $8.6 \mathrm{MPa}$ in $H=300 \mathrm{~m}, 14 \mathrm{MPa}$ at $500 \mathrm{~m}$, and $23 \mathrm{MPa}$ at 800 m (these values are calculated by $\sigma=k \gamma H$, taking $H=800$ $\mathrm{m}$ for example, $\sigma=k \gamma H=1.2 \times 24 \times 800=23 \mathrm{MPa}$ ). It can be seen that the left and right sides are subject to much greater compressive stress than the top and bottom sides. Due to the lower stress on the top and bottom sides in the unconstrained or weak constraint state, the beddings are prone to splitting failure taking into account that the direction of the beddings is parallel to the direction of stress acting on the left and right sides. According to the Poisson effect, a simplified rock column will deform laterally and some cracks, nearly paralleling to the upper and lower boundaries, generate in the water-resistant strata. Because of the loading difference on the top and bottom sides as mentioned earlier, the upward displacement on the upper side near the karst cavity is less than downward displacement on the lower side near the tunnel. Moreover, the greater the tunnel depth, then the greater the stress on the left and right sides of the waterresistant strata and, subsequently, the larger the lateral deformation, assuming lateral pressure coefficient was kept constant in the increase process of tunnel depth.

Therefore, in the initial stage $(t=10 \mathrm{~ms})$ for Table 7 , as the tunnel depth increases, the larger the area of upward displacement in the upper part of the water-resistant strata and the larger the area of downward displacement in the lower part, the larger the magnitude of the upward and downward displacements. However, because the downward displacement is always greater than the upward 
TABLE 6: The seepage pressure distribution in the water-resistant strata under the three cases of $H=300,500$, and $800 \mathrm{~m}$ at $t=10,40$, and $80 \mathrm{~ms}$.

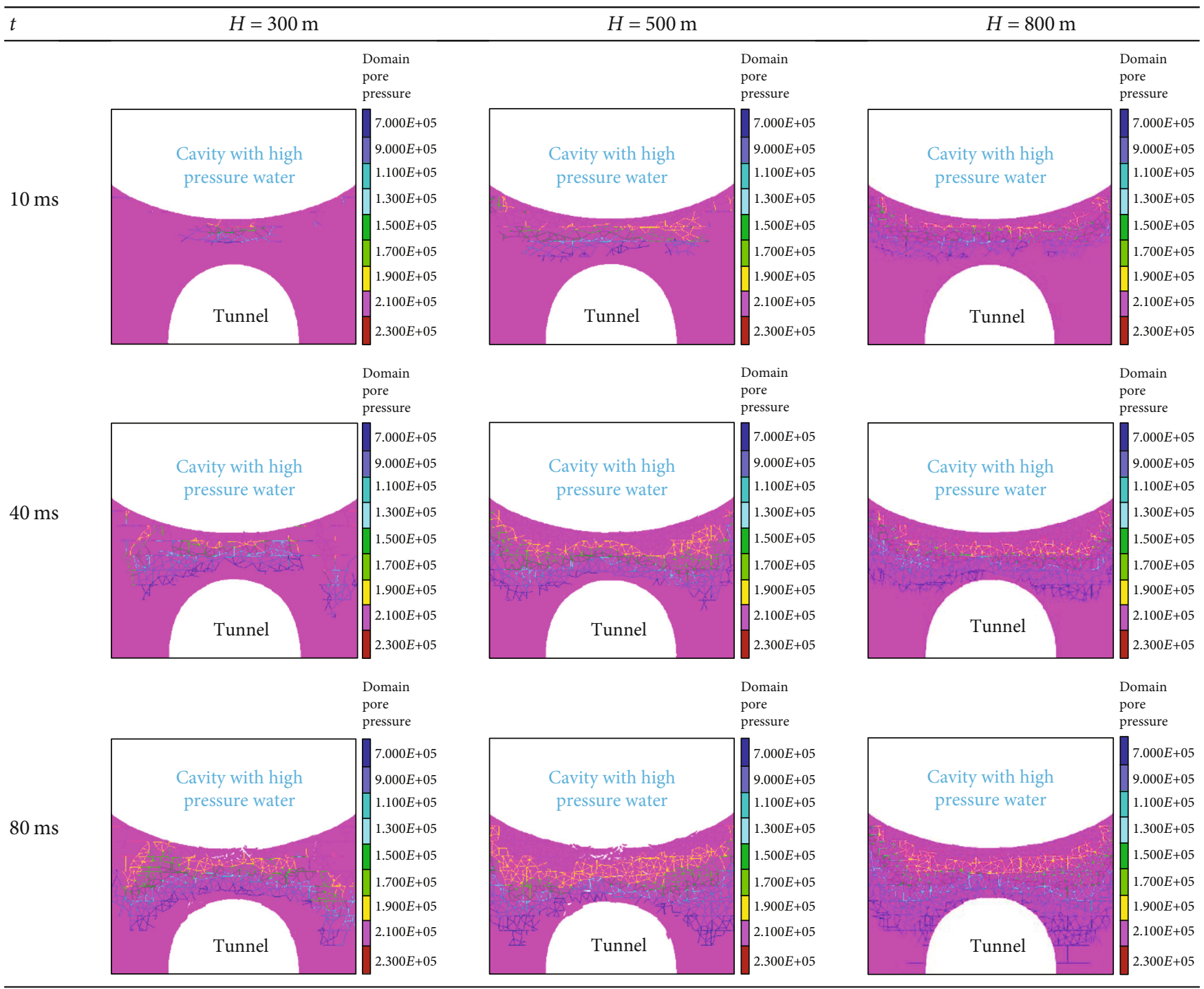

displacement, the area of downward displacement in the upper part of the water-resistant strata furtherly expands, resulting in the tendency of upward displacement in the upper part being weakened and offset and the deformation of water-resistant strata being mainly based on the upward displacement as shown in the second and third rows from Table 7. These analyses for the influence of tunnel depth on the displacement evolution characteristics in the waterresistant stability at the different times can be used to reveal the influence mechanism on the vertical displacement of karst water pressure in Table 5.

Figure 7 shows diachronic evolution characteristics of the vertical displacement at the 9 measuring points on HL1, HL2, and HL3 in the condition of $H=300,500$, and $800 \mathrm{~m}$. For the varied properties of any measuring point in this figure, it is easy to find that the vertical displacement and its growth speed or growth rate have a small difference between the two cases of $H=300 \mathrm{~m}$ and $H=500 \mathrm{~m}$, but far greater than those of $H=800 \mathrm{~m}$. For the former two cases, the change trend of the vertical displacement at each point is relatively uniform, and the water-resistant strata shows a clear tendency of instability failure. But for the later, the vertical displacement of each measuring point is significantly reduced, which indicates that the larger horizontal tectonic stress is beneficial for the stability of water-resistant strata between karst cavity and tunnel. Besides, the vertical displacement of arch crown greater than that of both sides of arch shoulders is verified again.

\section{Influence of Lateral Pressure Coefficient $(k)$}

5.1. Seepage Field Analysis of the Water-Resistant Strata under Different $k$. Table 8 shows the evolutionary processes of the seepage field in the water-resistant strata under the three cases of karst water pressure of $2 \mathrm{MPa}$, tunnel depth of $500 \mathrm{~m}$, and lateral pressure coefficient (case 7: $k=0.8$, case 8: $k=1.2$, and case 9: $k=1.6$ ) at $t=10 \mathrm{~ms}, 40 \mathrm{~ms}$, and $80 \mathrm{~ms}$. The column is the mechanical duration time, and the row is 


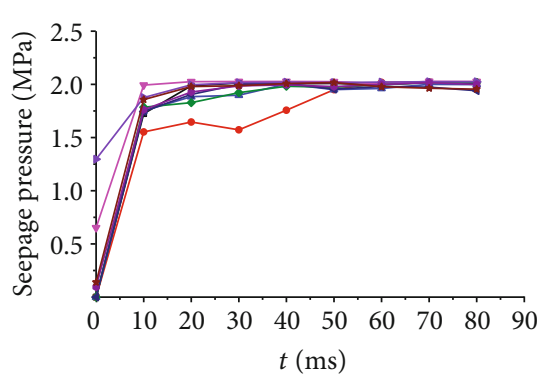

$$
\begin{aligned}
& \rightarrow h=300 \mathrm{~m}, \mathrm{nl} \text {; } \\
& \longrightarrow h=300 \mathrm{~m}, \mathrm{n} 2 \text {; } \\
& \text { ـ } h=300 \mathrm{~m}, \mathrm{n} 3 \text {; } \\
& \because h=500 \mathrm{~m}, \mathrm{n} 1 \text {; } \\
& \multimap h=500 \mathrm{~m}, \mathrm{n} 2 \text {; } \\
& \longleftarrow h=500 \mathrm{~m}, \mathrm{n} 3 \text {; } \\
& \rightarrow h=800 \mathrm{~m}, \mathrm{nl} \text {; } \\
& \multimap h=800 \mathrm{~m}, \mathrm{n} 2 \text {; } \\
& \text { ॠ } h=800 \mathrm{~m}, \mathrm{n} 3 \text {; }
\end{aligned}
$$

(a)

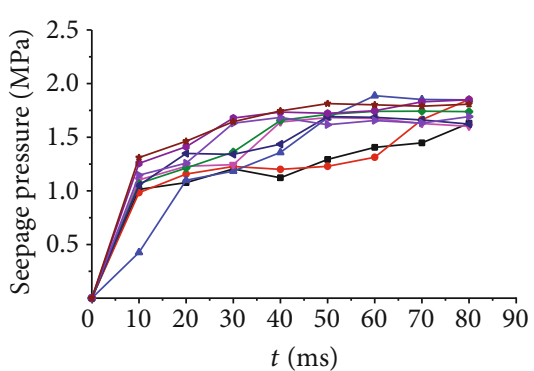

$$
\begin{aligned}
& \multimap h=300 \mathrm{~m}, \mathrm{n} 4 ; \\
& \multimap h=300 \mathrm{~m}, \mathrm{n} 5 ; \\
& \multimap h=300 \mathrm{~m}, \mathrm{n} 6 ; \\
& \multimap h=500 \mathrm{~m}, \mathrm{n} 4 ; \\
& \multimap h=500 \mathrm{~m}, \mathrm{n} 5 ; \\
& \longleftarrow h=500 \mathrm{~m}, \mathrm{n} 6 ; \\
& \rightarrow h=800 \mathrm{~m}, \mathrm{n} 4 ; \\
& \multimap h=800 \mathrm{~m}, \mathrm{n} 5 ; \\
& \rightarrow h=800 \mathrm{~m}, \mathrm{n} 6 ;
\end{aligned}
$$

(b)

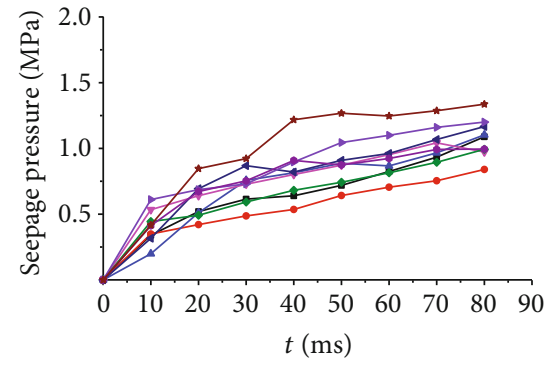

$\longrightarrow h=300 \mathrm{~m}, \mathrm{n} 7 ;$
$\longrightarrow h=300 \mathrm{~m}, \mathrm{n} 8 ;$
$\multimap h=300 \mathrm{~m}, \mathrm{n} 9 ;$
$\longrightarrow h=500 \mathrm{~m}, \mathrm{n} 7 ;$
$\longrightarrow h=500 \mathrm{~m}, \mathrm{n} 8 ;$
$\longleftarrow h=500 \mathrm{~m}, \mathrm{n} 9 ;$
$\rightarrow h=800 \mathrm{~m}, \mathrm{n} 7 ;$
$\multimap h=800 \mathrm{~m}, \mathrm{n} 8 ;$
$\longleftarrow h=800 \mathrm{~m}, \mathrm{n} 9 ;$

(c)

FIGURE 6: The trend of seepage pressure at the 9 measuring points in the conditions of $H=300$, 500, and $800 \mathrm{~m}$ : (a) n1 n3 on HL1; (b) n4 n6 on HL2; (c) n7 n9 on HL3.

the different lateral pressure coefficient. The karst water also infiltrates downward from the upper part to the bottom part in the water-resistant strata. The lateral pressure coefficient has some influences on the seepage pressure and seepage distribution scope by comparison with the results of three cases. It is found that the fracture at $t=80 \mathrm{~ms}$ under the condition of $k=0.8$ is more serious than that of another two cases of $k=1.2$ and $k=1.6$. It is indicated that the smaller the lateral pressure coefficient, the more serious the fracture of the water-resistant strata.

Figure 8 shows the trend of seepage pressure at the 9 measuring points under the three cases of $k=0.8,1.2$, and 1.6 , respectively. No matter what the value of lateral pressure coefficient is, the cracks in the water-resistant strata always easily propagate to the $n 1 \sim n 3$ measuring points in the upper part of the water-resistant strata, and the dissipated energy is less because the above measuring points are closer to the boundary of karst cavity. As a result, the seepage pressure of $\mathrm{n} 1 \sim \mathrm{n} 3$ measuring points always reaches a stable value which is close to the karst water pressure in karst cavity, as shown in Figure 8(a). Because the n4 n6 measuring points have a relatively long distance with karst cavity, the process of cracks channelling the cavity with high water pressure to reach the n4 n6 measuring points on HL2 will dissipate more energy. Therefore, the seepage pressure of n4 n6 measuring points reaches a relatively stable low value, approximately $1.5 \mathrm{MPa} \sim 1.8 \mathrm{MPa}$ as shown in Figure 8(b). At $t=80$ $\mathrm{ms}$, the water-resistant strata are still in the process of the seepage pressure accumulating-crack initiation and propagation, reaccumulating-crack initiation and propagation again under the three cases of $k=0.8,1.2$, and 1.6. As shown in Figure $8(\mathrm{c})$, the larger lateral pressure coefficient causes the increase of normal stress in crack in the water-resistant strata and then raises the critical water pressure as the threshold for hydraulic fracturing failure of cracks. Therefore, the fracture degree is higher and the fracture scope is larger under the low lateral pressure coefficient of $k=0.8$, and the seepage pressure of the $n 7 \sim n 9$ measuring points in the lower part of the water-resistant strata develops fully and is higher correspondingly under the circumstance of this lateral pressure coefficient.

\subsection{Displacement Field Analysis of the Water-Resistant Strata} under Different $k$. Table 9 shows the evolution processes of the displacement field in the water-resistant strata under the three cases of $k=0.8,1.2$, and 1.6 at $t=10 \mathrm{~ms}, 40 \mathrm{~ms}$, and $80 \mathrm{~ms}$. The disaster process of water-resistant strata based on displacement evolution is generally similar to Table 5 and Table 7. But the vertical displacement significantly differs from each other because of the different lateral pressure coefficient. In the different condition of $k=0.8,1.2$, and 1.6, the extension of the upward displacement area in the upper part of the water-resistant strata and the magnitude of the displacement increase with the increase of $k$. The underlying reason for this phenomenon is due to an increase of normal stress on the hydraulic cracks and its consequence of the critical water pressure for crack initiation arising from the horizontal load increase exerted on the left and right side of the water-resistant strata. It is very clear that the fracture zone and the vertical displacement decrease with the increase of $k$ at $t=40 \mathrm{~ms}$ and $80 \mathrm{~ms}$ mainly due to the increase of horizontal load realized by the lateral pressure coefficient. The fracture state is different in the water-resistant strata under the different lateral pressure coefficient. When the lateral pressure coefficient is relatively large $(k=1.2$ or 1.6$)$, the development trend of fracture is restrained by a larger lateral pressure coefficient and the fracture state is in the underdeveloped condition. However, the water-resistant strata are in the fractured state due to propagation and coalesce of hydraulic cracks for the smaller lateral pressure 
TABLe 7: The vertical displacement contour under the three cases of $H=300,500$, and $800 \mathrm{~m}$ at $t=10,40$, and $80 \mathrm{~ms}$.

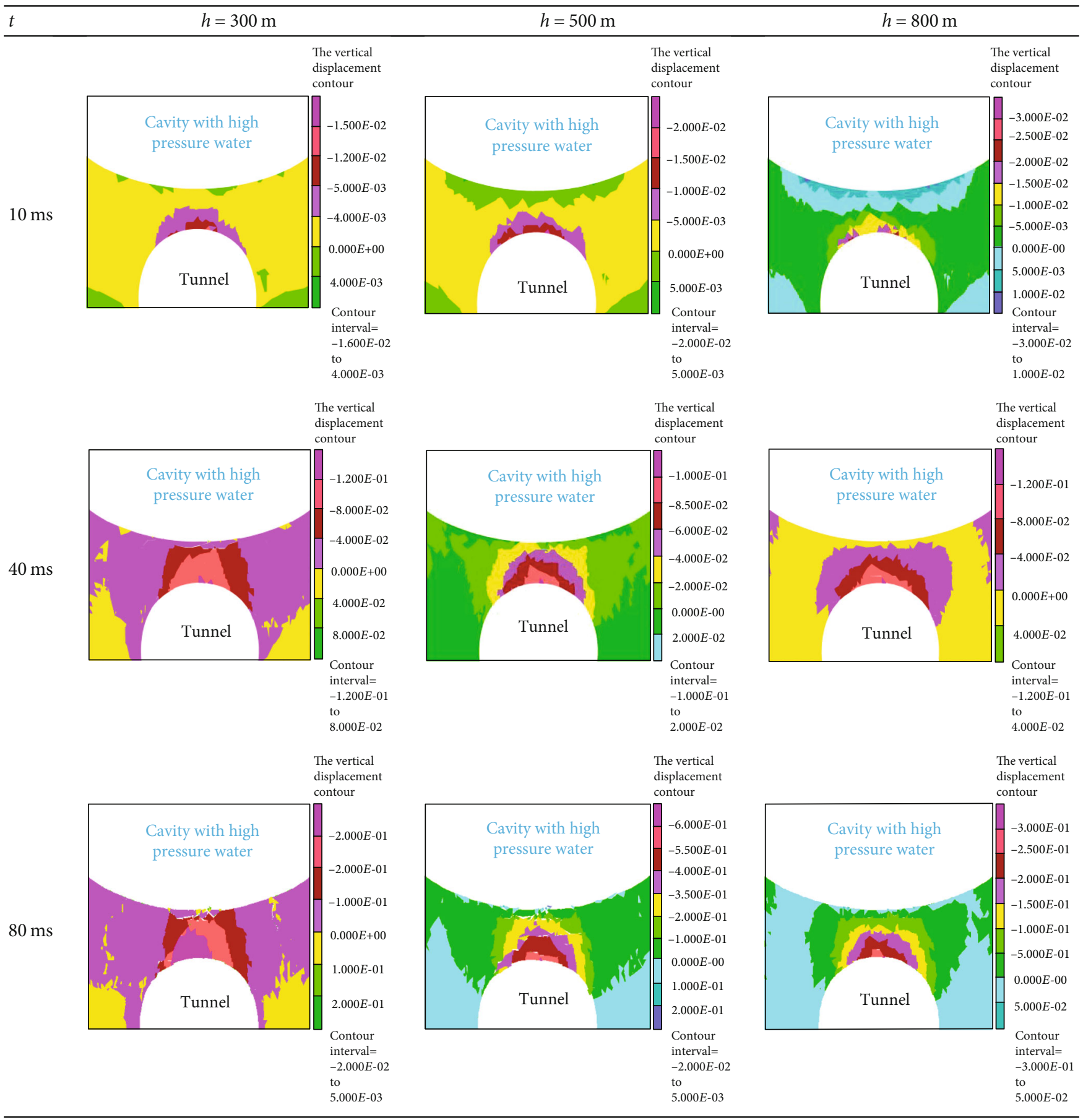

coefficient $(k=0.8)$, and the water inrush channel has fully formed at $t=80 \mathrm{~ms}$. It is concluded that the increase of lateral pressure coefficient can restrain the fracture development of the water-resistant strata and strengthen its stability from Table 9 and its systemic analysis.

Figure 9 shows the trend of the vertical displacement development of the 9 measuring points under the three cases of $k=0.8,1.2$, and 1.6 , respectively. Obviously, the vertical displacement of the same measuring points decreases signif- icantly with the increase of $k$. Under the condition that the lateral pressure coefficient is same, the closer to the tunnel vault and the deformation of the water-resistant strata are greater. For $k=1.2$ or 1.6 , the vertical displacement of the water-resistant strata is obviously smaller, but for $k=0.8$, the vertical displacement of the water-resistant strata increases rapidly and the final value of the vertical displacement at $t=80 \mathrm{~ms}$ is much larger than that for $k=1.2$ or 1.6. The vertical displacement in the lower part of the water- 


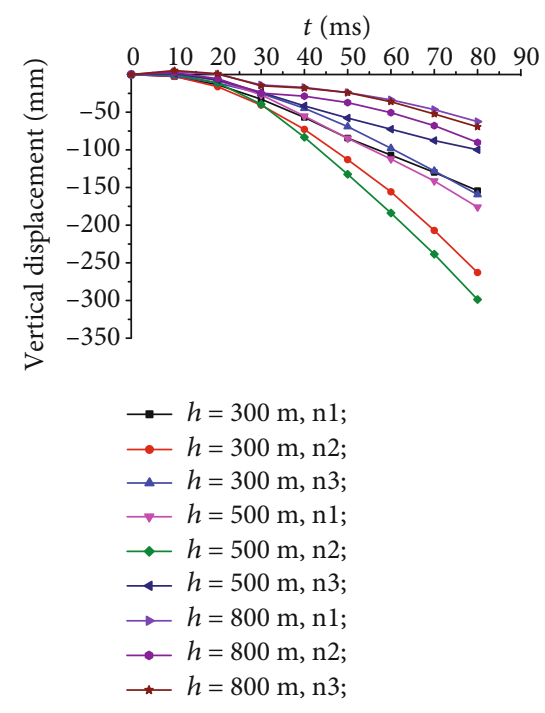

(a)

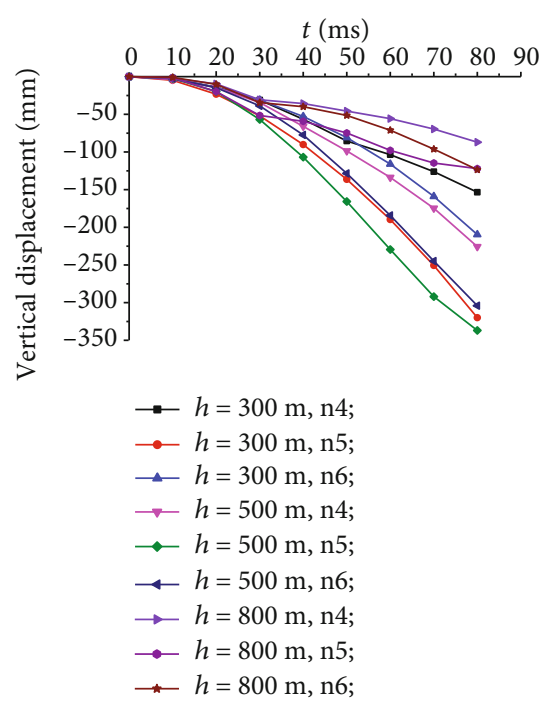

(b)

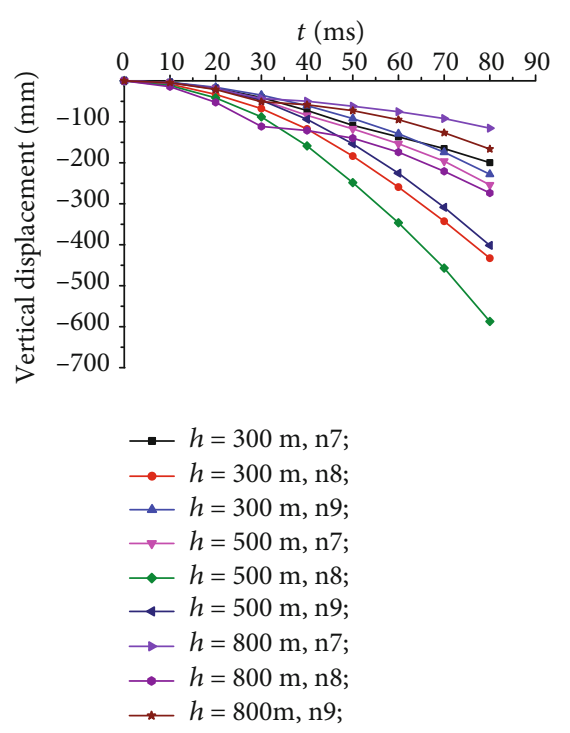

(c)

Figure 7: The vertical displacement at the 9 measuring points in the conditions of $H=300,500$, and $800 \mathrm{~m}$ : (a) n1 n3 on HL1; (b) n4 n6 on HL2; (c) n7 n9 on HL3.

resistant strata increases continuously with the decrease of $k$. It indicates that the smaller value of $k$ is unfavourable to the stability of the water-resistant strata.

\section{Discussion}

6.1. Comparative Analysis with Results of Previous Model Test. The main methods to study water inrush of karst tunnel are theoretical analysis, model test, field test, and numerical simulation. In the theoretical analysis method, it is difficult to analyse and describe the water inrush disaster process with highly nonlinear problems in mathematics. A field test is not used to carry out batch tests with multiple factors and variable conditions as desired and seriously threatens the tester's safety. Therefore, theoretical analysis and field test are suitable to be used as the main research method for water inrush of karst tunnel. According to schedule, the model test and numerical simulation can be used as the effective ways to carry out water inrush research and really simulate the disaster process of the water-resistant strata considering the coupling of various influential factors. The model test has many disadvantages of great expense, time-consuming, and lacking of ability to obtain the information in full field and microdynamic process. Numerical simulation can solve the above problems, and it has the function of visualizing the dynamic disaster process of water inrush and can rupture the microinformation. Therefore, numerical simulation is a promising, effective, and convenient method for studying water inrush of karst tunnel, but the validity of the results using this method needs to be verified by a model test and other methods.

In the published literature about water inrush of karst tunnel, researches on the influence of tunnel depth and lateral pressure coefficient on the stability of water-resistant strata by means of model test have not yet been found. A few scholars have done some researches on the influence of karst water pressure on the water-resistant strata stability, which provides the possibility to compare the research results in this paper through numerical simulation with previous results utilizing model test. Yang et al. conducted some physics model tests to study the disaster process of water-resistant strata and analysed the evolutionary properties of seepage pressure in the water-resistant strata with the increase of karst water pressure [21]. Zhu used a self-developed testing system to study the influence of the karst water pressure on the deformation and deterioration of the water-resistant strata and found that the vertical displacement of the water-resistant strata gradually increased with the growth of karst water pressure [27]. The research results of this article are highly consistent with the abovementioned achievements obtained by the use of model tests, which proves the reliability of the numerical simulation method and the effectiveness of conclusions in this paper.

6.2. Comprehensive Effect of Three Kinds of Influential Factors. The instability and then water inrush of the waterresistant strata between tunnel and karst cavity with high pressure water are essentially a manifestation of local failure in surrounding rock mass of karst tunnel under the combined action of karst water pressure and disturbance of tunnel excavation. Karst water pressure is one kind of load directly acting on the water-resistant strata and causes fluid-solid coupling effect in the disaster process of the water-resistant strata. We can see that the seepage and failure scope extend obviously and the fracture degree increases quickly with the increase of karst water pressure from Table 4. Therefore, the water pressure of karst cavity is the effective factor affecting the stability analysis of waterresistant strata based on the research of this paper and many published papers by theoretical analysis, numerical simulation, model tests, and field tests [28]. 
TABLE 8: The seepage pressure distribution in the water-resistant strata under the three cases of $k=0.8,1.2$, and 1.6 at $t=10,40$, and 80 ms.

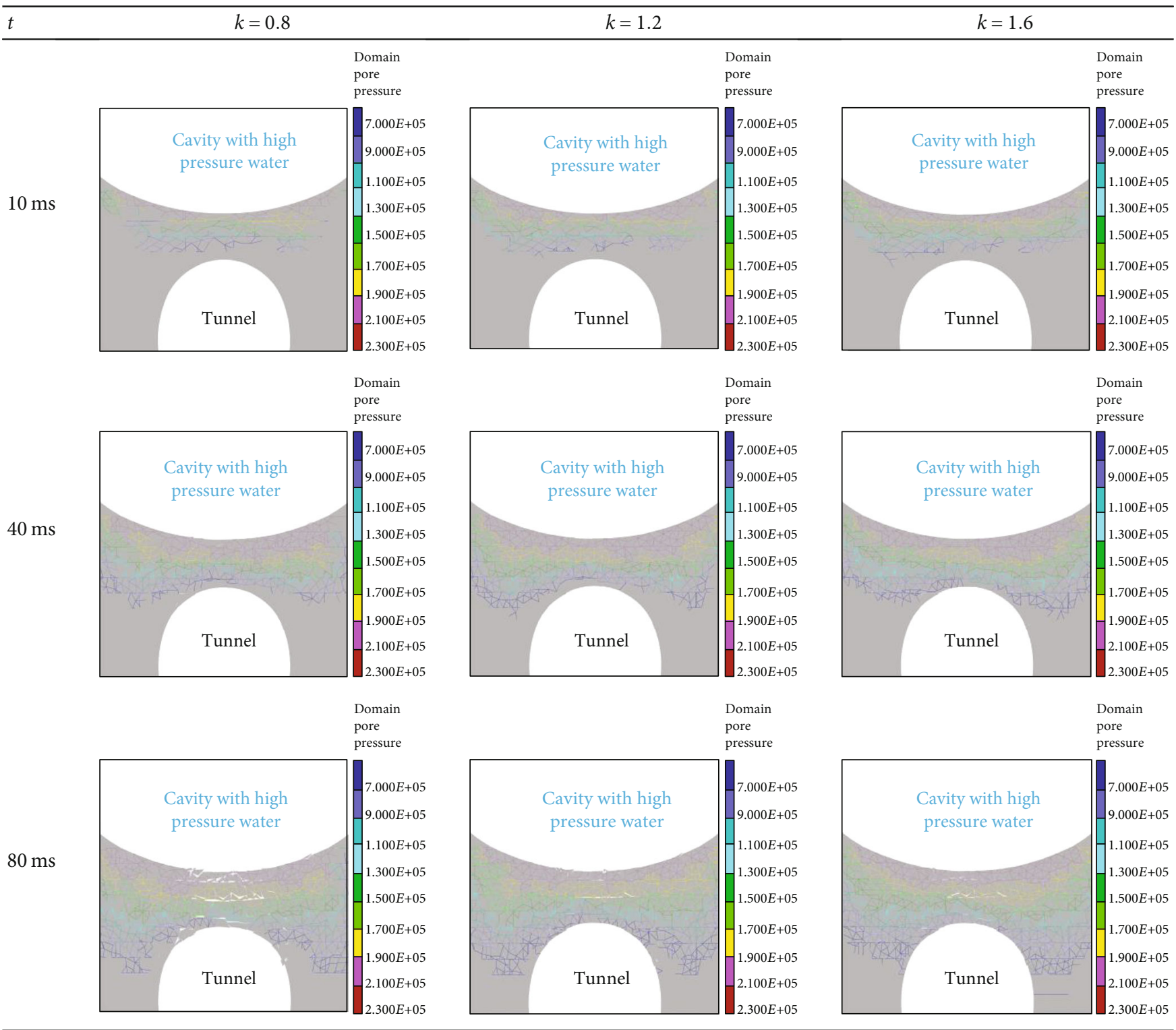

If tunnel is not constructed in strata, the water-resistant strata do not exist and the problems of the water-resistant strata stability will not exist. Tunnel excavation disturbance makes the water-resistant strata lose the lower support from the rock mass, and therefore, the water-resistant strata are in the unloading and stress adjustment condition and the critical water pressure of the water-resistant strata failure will decrease, eventually causing the water-resistant strata instability and water inrush. The degree of the unloading and stress adjustment is directly related to the geostress environment of the tunnel-karst system that is mainly determined by the tunnel depth and lateral pressure coefficient, and in consequence, tunnel depth and lateral pressure coefficient are the influential parameters for the water-resistant strata stability. Tables 6-9 and Figures 6-9 illustrate that the stability of water-resistant strata between karst cavity and tunnel decreases on the whole with the growth of tunnel depth, but with the decline of lateral pressure coefficient.

At present, there are few researches on the comprehensive effect of karst water pressure, tunnel depth, and lateral pressure coefficient on the stability of water-resistant strata. Zhang et al. established the theoretical relationship between stress intensity factor of crack tip in surrounding rock mass and tunnel depth under excavation unloading disturbance [29]. Guo and Qiao analysed the tendency of critical water pressure for the water-resistant strata failure with the normal stress on the crack in the water-resistant strata [30]. According to these above achievements, it is concluded that tunnel depth can strengthen the stress intensity factor, decreasing the water-resistant strata stability, and the lateral pressure coefficient is able to heighten the critical water pressure, for the stability. These conclusions are consistent with the 


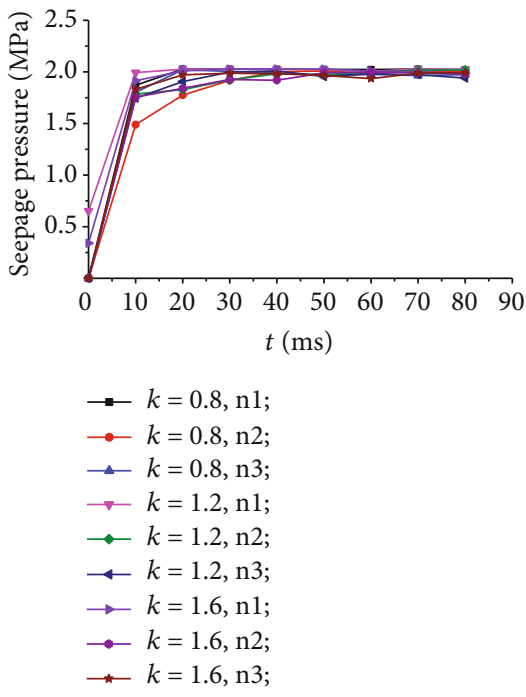

(a)

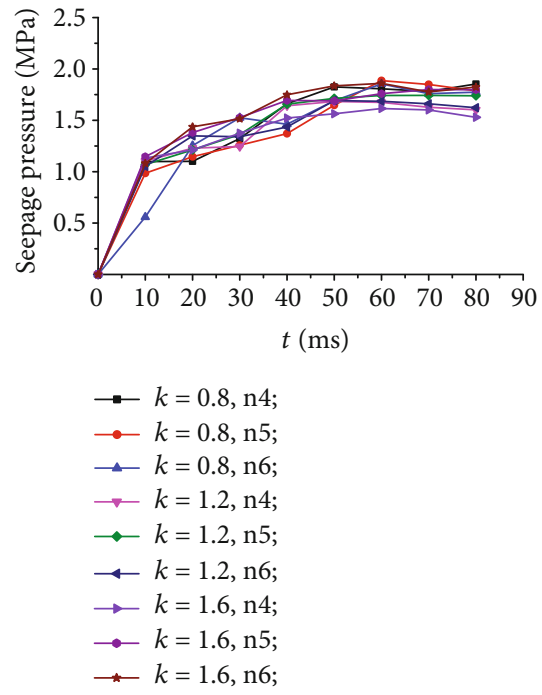

(b)

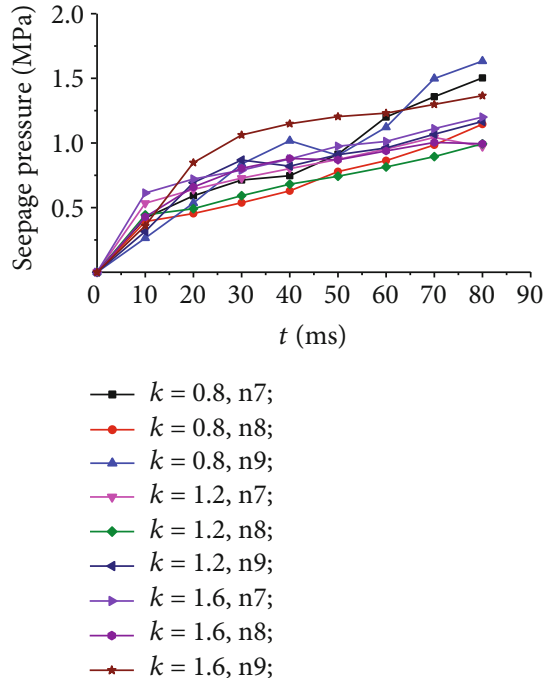

(c)

FIGURE 8: The trend of seepage pressure at the 9 measuring points in the conditions of $k=0.8,1.2$, and 1.6: (a) n1 n3 on HL1; (b) n4 n6 on HL2; (c) n7 n9 on HL3.

obtained results in Sections 4 and 5. These mean that tunnel depth amplifies the effect of karst water pressure $p$ and the lateral pressure coefficient weakens the influence of $p$.

6.3. Stability Analysis Based on Energy Evolutionary Properties. As mentioned before, the water-resistant strata with quasi-masonry structure composed of discrete small rock blocks, bedding, and cross joints are heterogeneous, discontinuous, nonlinear, and highly discrete. Therefore, it is difficult to accurately and quantitatively describe the mechanical behaviour of all discrete blocks, joints, and cracks in the analysis of the instability process of water-resistant strata and evolution characteristics of water inrush under the condition that laboratory tests to investigate the behaviour of small-scale rock samples and structure planes are unlikely to accurately reflect the real state. However, this complicated phenomenon can be dealt with and grasped from the whole utilizing the theories of system science. As a whole, karst cavity, tunnel, and the water-resistant strata (surrounding rock mass) are regarded as an open system [19]. There exists always the energy exchange between this system and environment, and the process of water inrush in karst tunnel is seen as the energy release process of the above system. In this process, energy dissipation is caused by crack initiation-propagation-coalesce and plastic deformation in the water-resistant strata. The rock fragments separated from the water-resistant strata move at a certain speed, and these blocks release the system energy [31]. Therefore, the dissipated and kinetic energy can be used as an index to characterize the disaster condition of water-resistant strata [32].

Taking three cases under different karst water pressure of $p=1,2$, and $3 \mathrm{MPa}$ in Section 3 as examples, the evolutionary characteristics of the dissipated and kinetic energy $\left(U_{d}\right.$ and $U_{k}$ ) in the disaster process of water inrush, calculated by the energy calculation module of UDEC program, is shown in Figures 10 and 11. In the period of $0 \sim 20 \mathrm{~ms}$, the evolutionary processes of $U_{k}$ and $U_{d}$ are almost identical. During this period, a few cracks develop steadily and obvious displacement appears in the water-resistant strata. But after $20 \mathrm{~ms}$, $U_{d}$ gradually tends to one constant value and $U_{k}$ fast reduces a lower value for $p=1 \mathrm{MPa}$, which indicates that the hydraulic cracks gradually stop propagating and the water-resistant strata are in the condition of stability for avoiding water inrush. These phenomena are well consistent with those revealed in Table 4 and Figure 4 . But in the cases of $p=2$ or $3 \mathrm{MPa}, U_{k}$ and $U_{d}$ increase rapidly with the increase of $p$ , and their growth rates also increase. These indicate that the cracks continue to propagate and the propagation speed is accelerated. The number of hydraulic cracks continues to increase, and displacement continues to accelerate. Then, the water-resistant strata become unstable and water inrush occurs, although the $U_{d}$ and $U_{k}$ in conditions of $p=2 \mathrm{MPa}$ and $p=3 \mathrm{MPa}$ have the same evolutionary trend in Figures 10 and 11 . But after $20 \mathrm{~ms}$, by comparing the two cases of $p=2 \mathrm{MPa}$ and $p=3 \mathrm{MPa}$, not only the kinetic energy and dissipated energy of the system are significantly different, but also the growth rate of $U_{d}$ and $U_{k}$ is also the same situation. It demonstrates that the greater the karst water pressure, the more likely to be failure and water inrush. These results are good agreement with the displacement and cracks in Tables 4 and 5 .

6.4. Engineering Measures to Control and Prevent Water Inrush. The global karst distribution area is 22 million square kilometres, which accounts for $15 \%$ of the global land area. Among them, mainly concentrated distribution was in Yunnan-Guizhou Plateau and Hunan-Guangxi Hilly Basin in China; Massif Central, Ural Mountains in Russia; and Indiana State and Kentucky State in the Middle East of the United States. It is inevitable that the tunnel will expose karst structure or closely pass through the affected area when some 
TABle 9: The vertical displacement contour under the three cases of $k=0.8,1.2$, and 1.6 at $t=10,40$, and $80 \mathrm{~ms}$.

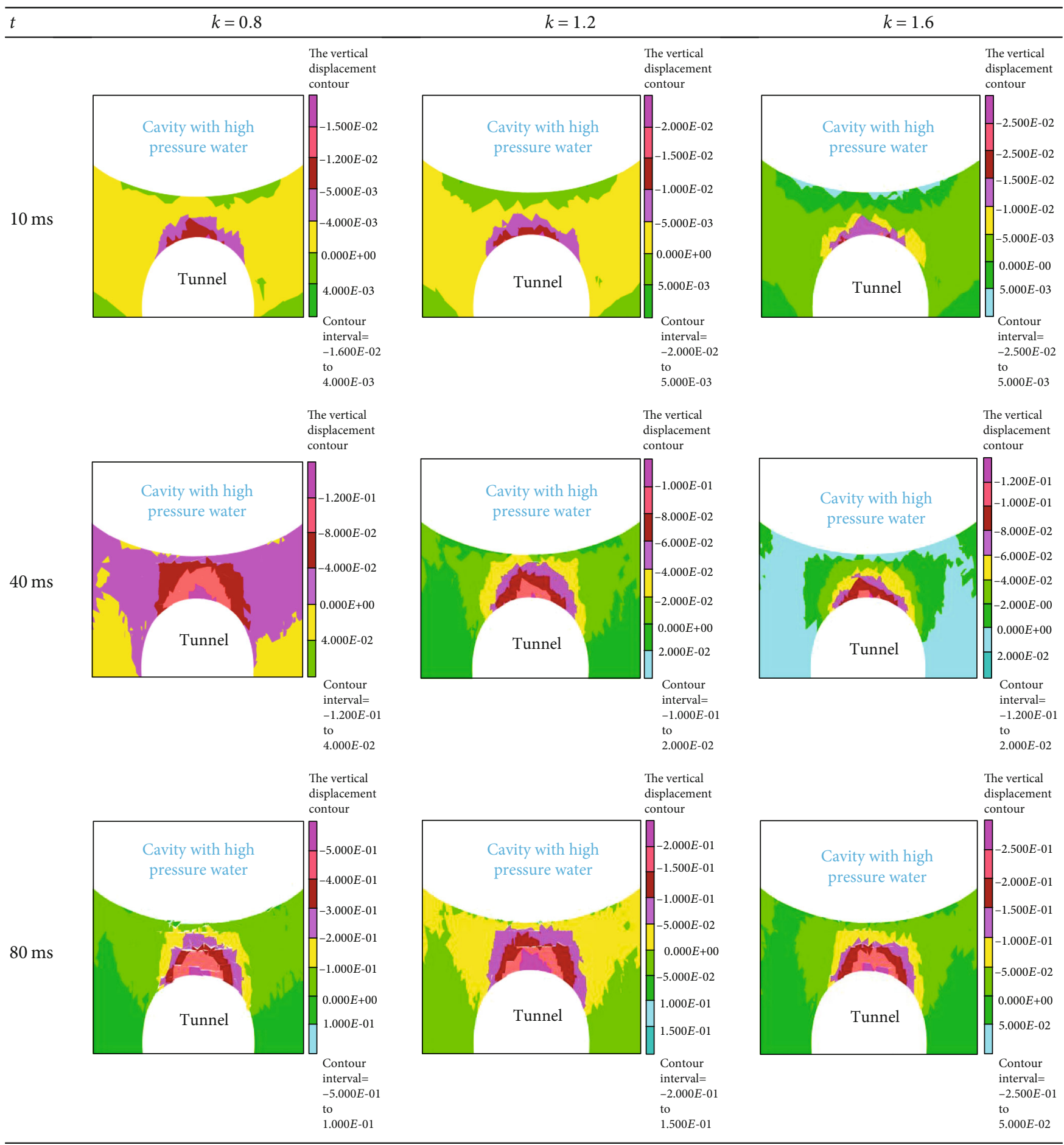

tunnels are planned to be constructed in the karst area. Water inrush disaster is often caused by the instability of waterresistant strata [33]. The results of this paper show that karst water pressure, tunnel depth, and lateral pressure coefficient have obvious effects on the water-resistant strata stability. Tunnel depth and lateral pressure coefficient are important consideration factors in tunnel design stage (route selection). But these are the immutable geological environment in the construction stage of tunnel. This part mainly discusses the control and prevention measures of water inrush disaster in karst tunnel from the perspective of influential law of karst water pressure. Figure 12 shows the variation characteristics of seepage pressure and vertical displacement of $\mathrm{n} 2, \mathrm{n} 5$, and n8 under three cases of $H=500 \mathrm{~m}, k=1.2$, and $p=1 \mathrm{MPa}$, $2 \mathrm{MPa}$, and $3 \mathrm{MPa}$ at $t=10 \mathrm{~ms}, 40 \mathrm{~ms}$, and $80 \mathrm{~ms}$. According to Figure 12, the seepage pressure and vertical displacement of the three measuring points increase obviously with the increase of karst water pressure. Therefore, karst water 


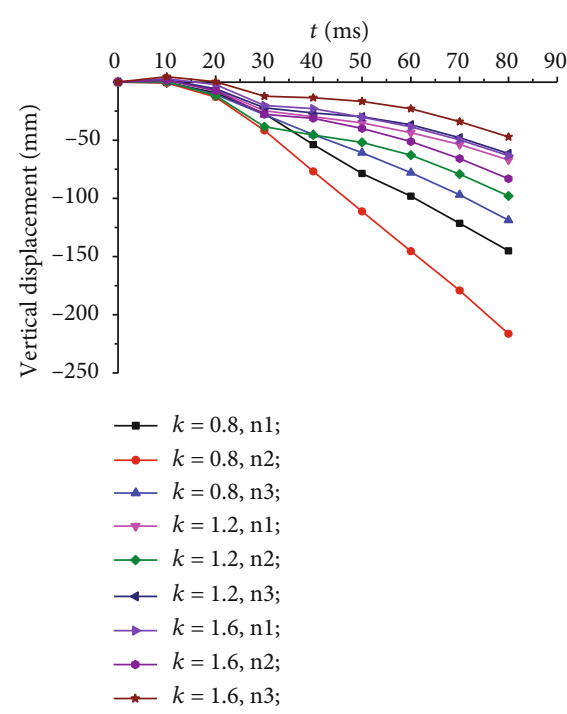

(a)

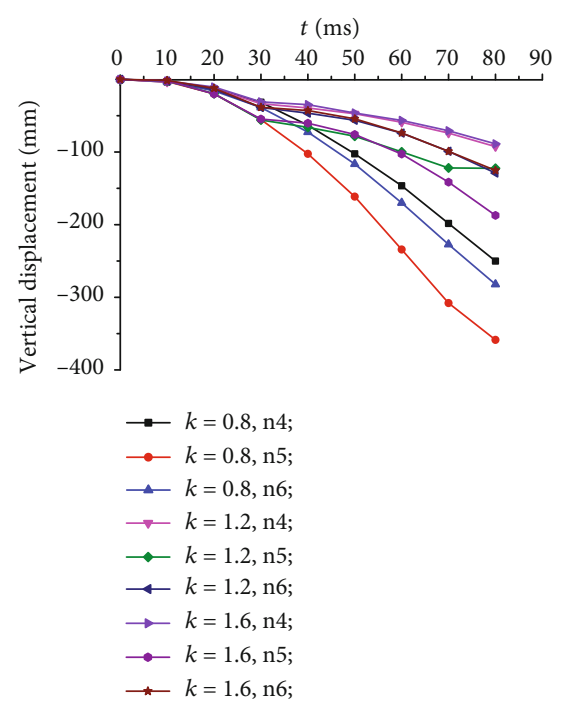

(b)

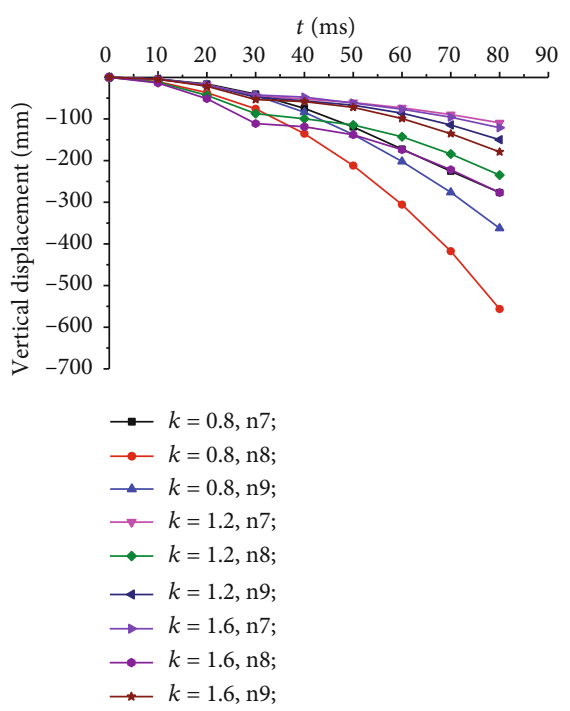

(c)

FIGURE 9: The vertical displacement at the 9 measuring points in the conditions of $k=0.8,1.2$, and 1.6: (a) n1 n3 on HL1; (b) n4 n6 on HL2; (c) n7 n9 on HL3.

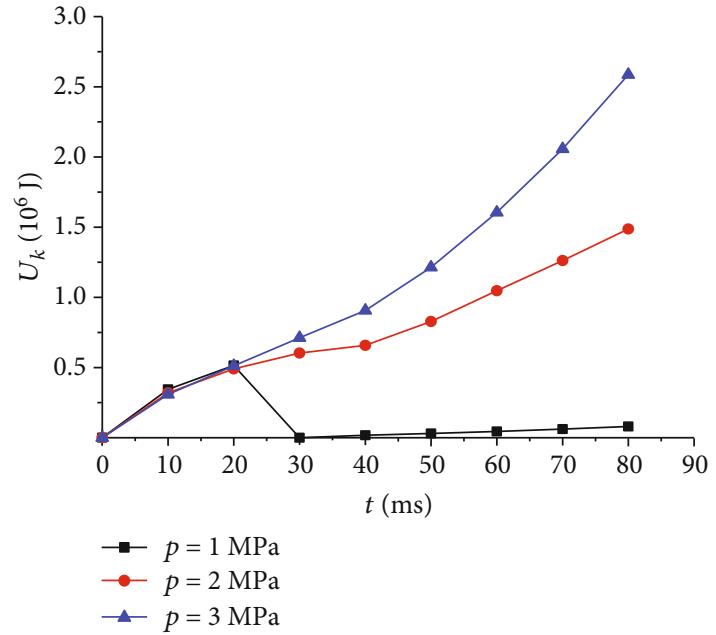

FIGURE 10: The evolution process of $U_{k}$ of the system with $p=1,2$, and $3 \mathrm{MPa}$.

pressure in the cavity is an extremely important factor affecting the water-resistant strata stability, and additionally, the water-resistant performance and impermeability are also critical to control and prevent water inrush.

According to the above analysis, the pros and cons aspects of karst water pressure and water-resistant performance of the rock mass between cavity with high water pressure and tunnel, mainly considered during the process of the game process of the instability of water-resistant strata and water inrush, are the key to control and prevent water inrush disaster of karst tunnel. The water inrush disaster of karst tunnel is caused by reducing the critical water pressure of water-resistant strata failure due to tunnel excavation disturbance, and hence, reducing karst water pressure and increasing the critical water pressure of rock mass are the main

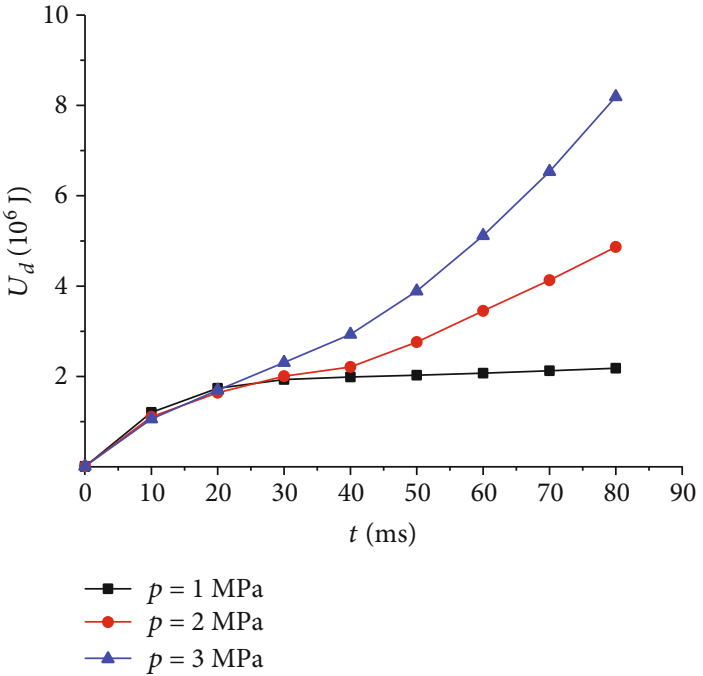

FIgURE 11: The evolution process of $U_{d}$ of the system with $p=1,2$, and $3 \mathrm{MPa}$.

measures to contain water inrush of karst tunnel. Some draining holes or tunnels are usually set up to release the stored energy in karst cavity and reduce karst water pressure in the engineering practice. Finally, the above method makes karst water pressure in karst tunnel smaller than the critical water pressure of water-resistant strata failure, and then the water inrush disaster in karst is avoided successfully. Another method of increasing the critical water pressure of the waterresistant strata is mainly achieved by improving the waterresistant performance of rock mass itself. In engineering practices, on the one hand, the partial excavation of small section and short progress is adopted to avoid excessive excavation disturbance and protect the water-resistant performance of the rock mass. On another hand, grouting and 


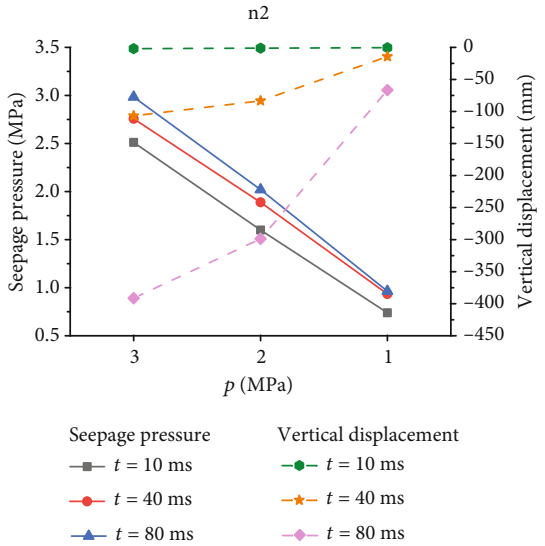

(a) $\mathrm{n} 2$

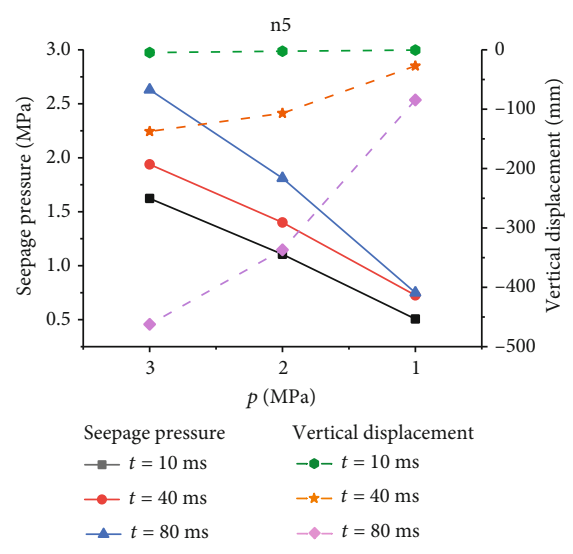

(b) n5

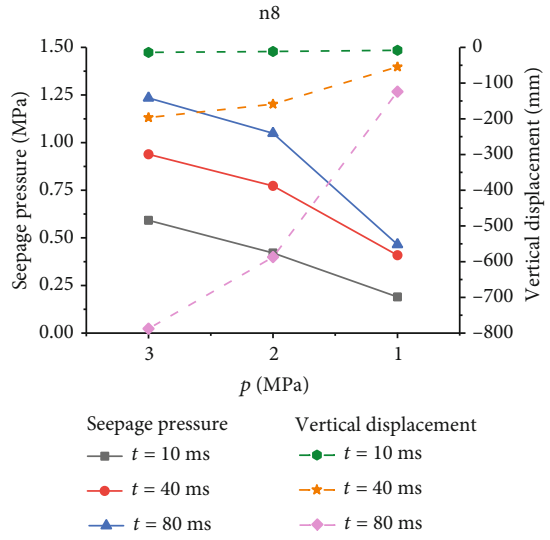

(c) n8

FIGURE 12: Relationship between seepage pressure and vertical displacement of three measuring points and karst water pressure at different time.

other prereinforcement method are implemented to reinforce the water-resistant strata and improve the waterresistant performance and impermeability [34-36].

\section{Conclusions}

Water inrush is one of the main geological disasters in the karst tunnel excavation. To investigate the evolutionary characteristics of seepage pressure and displacement in the disaster process of water inrush under different combined conditions of karst water pressure, tunnel depth, and lateral pressure coefficient, a series of numerical simulation analyses based on DEM were conducted utilizing the numerical models considering the quasi-masonry structure properties of water-resistant strata. Some conclusions can be drawn in the following:

(1) The seepage pressure of measuring points increases with the increase of kart water pressure. The seepage pressure illustrates a decreasing state from HL1 to HL3 and the time of arrival to a stable value for the seepage pressure at different measuring point varies obviously, and it shows the time effect. The displacement increases almost linearly with time under lower karst pressure, and the corresponding relationship curve demonstrates parabolical properties in condition of higher karst water pressure. The fracture area, fracture degree, and seepage pressure level increase quickly with the increase of karst water pressure

(2) The velocity of water seepage and crack propagation varies greatly with tunnel depth. The area and magnitude of displacement in the water-resistant strata increase with tunnel depth. The distribution area of water and hydraulic fractures obviously increase with the increase of tunnel depth. The larger the tunnel depth, the greater the scale and coalescence of fractures formed and the more likely the water inrush to occur in a short time. The stability of water- resistant strata decreases on the whole with the growth of tunnel depth

(3) No matter what the value of lateral pressure coefficient is, the seepage pressure of $n 1 \sim n 3$ measuring points always reach a stable value which is close to the karst water pressure and those of $n 4 \sim n 9$ reaches a relatively stable lower value. The vertical displacement decrease with the increase of lateral pressure coefficient. The larger lateral pressure coefficient raises the critical water pressure. The increase of lateral pressure coefficient can restrain the fracture development and strengthen stability. The fracture state is different under the different lateral pressure coefficients

(4) The research results of this article by numerical simulation are highly consistent with the achievements obtained utilizing model tests. Tunnel depth amplifies the effect of karst water pressure $p$, and lateral pressure coefficient weakens the influence of p. Stability analysis based on energy properties can be the important method to analyse and characterize the disaster process and condition of the waterresistant strata. In view of the important influence on the stability of water-resistant strata, the pros and cons aspects of karst water pressure and waterresistant performance are the key to control and prevent water inrush in karst tunnel

\section{Data Availability}

The raw/processed data required to reproduce these findings cannot be shared at this time as the data also form part of an ongoing study.

\section{Conflicts of Interest}

The authors declare that they have no conflicts of interest. 


\section{Acknowledgments}

This study was financially supported by the National Natural Science Foundation of China (Grant No. 51778215), the National Key Basic Research and Development Plan (973 Plan) Project (Grant No. 2013CB036003), the China Postdoctoral Science Foundation Fund (Grant No. 2018M631114), and the Open Foundation of the State Key Laboratory (KF2020-07).

\section{References}

[1] Q. L. Cui, S. L. Shen, Y. S. Xu, H. N. Wu, and Z. Y. Yin, "Mitigation of geohazards during deep excavations in karst regions with caverns: a case study," Engineering Geology, vol. 11, pp. 194-204, 2015.

[2] Y. X. Lv, Y. J. Jiang, H. Wei, M. Cao, and Y. Mao, "A review of the effects of tunnel excavation on the hydrology, ecology, and environment in karst areas: current status, challenges, and perspectives," Journal of Hydrology, vol. 586, p. 124891, 2020.

[3] S. C. Li, Z. Q. Zhou, L. P. Li, Q. Q. Zhang, and S. S. Shi, "Risk assessment of water inrush in karst tunnels based on attribute synthetic evaluation system," Tunnelling and Underground Space Technology incorporating Trenchless Technology Research, vol. 38, pp. 50-58, 2013.

[4] P. Jeannin, A. Yves, and D. Malard, "Assessing karst-hydraulic hazards in tunneling-the Brunnmühle spring system-Bernese Jura, Switzerland," Environmental Earth Sciences, vol. 74, no. 12, pp. 7655-7670, 2015.

[5] Y. J. Zhao, F. G. Wang, C. S. Li, Y. Q. Cao, H. L. Tian, and L. Borrelli, "Study of the corrosion characteristics of tunnel fissures in a karst area in Southwest China," Geofluids, vol. 2018, 19 pages, 2018.

[6] Y. G. Xue, F. M. Kong, D. H. Qiu, M. X. Sun, and Y. Zhao, “The classifications of water and mud/rock inrush hazard: a review and update," Bulletin of Engineering Geology and the Environment, vol. 80, no. 3, pp. 1907-1925, 2021.

[7] X. X. Liu, S. L. Shen, Y. S. Xu, and Z. Y. Yin, “Analytical approach for time-dependent groundwater inflow into shield tunnel face in confined aquifer," International Journal for Numerical and Analytical Methods in Geomechanics, vol. 42, no. 4, pp. 655-673, 2018.

[8] M. Q. Zhang and S. W. Liu, "The analysis on the features of karst water burst in the Yuanliangshan tunnel," Chinese Journal of Geotechnical Engineering, vol. 27, no. 4, pp. 422-426, 2005.

[9] Y. Zhuo and G. Q. Sun, "Grouting construction technology of high pressure and rich water fault F11 in Qiyueshan tunnel," Engineering Science, vol. 11, no. 12, pp. 82-86, 2009.

[10] J. Q. Guo, G. Y. Wang, and L. W. Ren, "Geological features of karst and its development pattern of Yiwan railway," The Chinese Journal of Geological Hazard and Control, vol. 24, no. 2, pp. 72-78, 2013.

[11] Z. H. Xu, J. Wu, S. C. Li, B. Zhang, and X. Huang, "Semianalytical solution to determine minimum safety thickness of rock resisting water inrush from filling-type karst caves," International Journal of Geomechanics, vol. 18, no. 2, pp. 1-11, 2018.

[12] H. Fu, L. H. Zhao, T. H. Ling, and X. L. Yang, "Rock mass collapse mechanism of concealed karst cave beneath deep tunnel," International Journal of Rock Mechanics and Mining Sciences, vol. 91, pp. 133-138, 2017.
[13] J. Q. Guo, J. X. Chen, F. Chen, S. X. Huang, and H. Y. Wang, "Using the Schwarz alternating method to identify critical water-resistant thickness between tunnel and concealed cavity," Advances in Civil Engineering, vol. 2018, 15 pages, 2018.

[14] H. Xin, S. C. Li, Z. H. Xu, M. Guo, and X. S. Shi, “An attribute recognition model for safe thickness assessment between concealed karst cave and tunnel," Journal of Central South University, vol. 26, no. 4, pp. 955-969, 2019.

[15] Z. H. Yang, Y. X. Li, J. S. Xu, and H. B. Xiao, "Upper bound stability analysis for confining rocks considering the circular existence of filled karst cave around tunnels," Journal of Hunan Univeristy (Natural Science), vol. 44, no. 5, pp. 122-131, 2017.

[16] L. Qin, L. Wei, J. X. Chen, Y. B. Luo, and P. Huang, "Stability analysis of water-resistant strata in karst tunnel based on releasable elastic strain energy," Mathematical Problems in Engineering, vol. 2017, 9 pages, 2017.

[17] R. L. Shan, X. N. Zhang, and M. Lu, "Numerical application of safe thickness between a tunnel and surrounding concealed caves," Geotechnical and Geological Engineering, vol. 36, no. 1, pp. 95-104, 2018.

[18] D. D. Pan, S. C. Li, Z. H. Xu, P. Lin, and X. Huang, "Experimental and numerical study of the water inrush mechanisms of underground tunnels due to the proximity of a water-filled karst cavern," Bulletin of Engineering Geology and the Environment, vol. 78, no. 8, pp. 6207-6219, 2019.

[19] L. P. Li, Study on CatastroPhe Evolution Mechansim of Karst Water Inrush and Its Eengineering Application of High Risk Karst Tunnel, [Ph.D. thesis], Shandong University, Jinan, 2009.

[20] D. X. Liang, Z. Q. Jiang, S. Y. Zhu, Q. Sun, and Z. W. Qian, "Experimental research on water inrush in tunnel construction," Natural Hazards, vol. 81, no. 1, pp. 467-480, 2016.

[21] W. M. Yang, Z. D. Fang, X. Yang, S. S. Shi, and J. Wang, "Experimental study of influence of karst aquifer on the law of water inrush in tunnels," Water, vol. 10, no. 9, pp. 1-24, 2018.

[22] D. D. Pan, S. C. Li, Z. H. Xu, L. P. Li, and W. Lu, "Model tests and numerical analysis for water inrush caused by karst caves filled with confined water in tunnels," Chinese Journal of Geotechnical Engineering, vol. 40, no. 5, pp. 828-836, 2018.

[23] F. Zhang, E. Dontsov, and M. Mack, "Fully coupled simulation of a hydraulic fracture interacting with natural fractures with a hybrid discrete-continuum method," International Journal for Numerical and Analytical Methods in Geomechanics, vol. 41, no. 13, pp. 1430-1452, 2017.

[24] F. S. Zhang, B. Damjanac, and S. Maxwell, "Investigating hydraulic fracturing complexity in naturally fractured rock masses using fully coupled multiscale numerical modeling," Rock Mechanics and Rock Engineering, vol. 52, no. 12, pp. 5137-5160, 2019.

[25] J. Q. Guo, Study on Against-Inrush Thickness and Water Burst Mechanism of Karst Tunnel, [Ph.D. thesis], Beijing Jiaotong University, Beijing, 2011.

[26] Z. Y. He, Study on Progressive Failure and Safety Thickness of Water-Resistant Strata during Karst Tunnel Constructed by Drilling and Blasting Method, M.S. Dissertation, Henna polytechnic university, Jiaozuo Henan, 2017.

[27] W. X. Zhu, Study on Mechanism of Water Inrush in Muddy Limestone Karst Tunnel After Wetting and Drying Cycles, [Ph.D. thesis]., China University of Mining and Technology, Beijing, 2018. 
[28] Z. Huang, X. Z. Li, S. J. Li, K. Zhao, and R. Zhang, "Investigation of the hydraulic properties of deep fractured rocks around underground excavations using high-pressure injection tests," Engineering Geology, vol. 245, pp. 180-191, 2018.

[29] F. D. Zhang, B. J. Shen, and Y. H. Kang, "Water inrush failure mechanism of mining floor under unloading effect," Rock and Soil Mechanics, vol. 37, no. 2, pp. 431-438, 2016.

[30] J. Q. Guo and C. S. Qiao, "Study on water-inrush mechanism and safe thickness of rock wall of karst tunnel face," Journal of the China Railway Society, vol. 34, no. 3, pp. 105-111, 2012.

[31] J. Q. Jiang, "Research on mechanical behaviours and seismic stability of reinforced red-sandstone granular soil retaining wall," [Ph.D. thesis], Central South University, Changsha, 2010.

[32] Z. J. Zhang, J. B. Zhu, B. Wang, Z. J. Feng, and B. Lu, “The damage and shear dilation property evolution based on energy dissipation mechanism of gneissic granite," Chinese Journal of Rock Mechanics and Engineering, vol. 37, no. S1, pp. 34413448, 2018.

[33] S. S. Lin, S. L. Shen, A. Zhou, and Y. S. Xu, "Novel model for risk identification during karst excavation," Reliability Engineering \& System Safety, vol. 209, pp. 107435-107448, 2021.

[34] N. Zhang, S. L. Shen, A. N. Zhou, and H. M. Lyu, "Challenges of earth-pressure-balance tunnelling in weathered granite with boulders," Proceedings of the Institution of Civil EngineersGeotechnical Engineering, vol. 2020, pp. 1-37, 2020.

[35] E. Khalid, S. L. Shen, W. C. Cheng, and A. Arulrajah, "Cutterdisc consumption during earth pressure balance tunnelling in mixed strata," Proceedings of the Institution of Civil EngineersGeotechnical Engineering, vol. 171, no. 4, pp. 363-376, 2018.

[36] K. Elbaz, S.-L. Shen, Y. Tan, and W.-C. Cheng, "Investigation into performance of deep excavation in sand covered karst: a case report," Soils and Foundations, JGS, vol. 58, no. 4, pp. 1042-1058, 2018. 